(2) norden

\title{
The land-use sector within the post-2020 climate regime
}
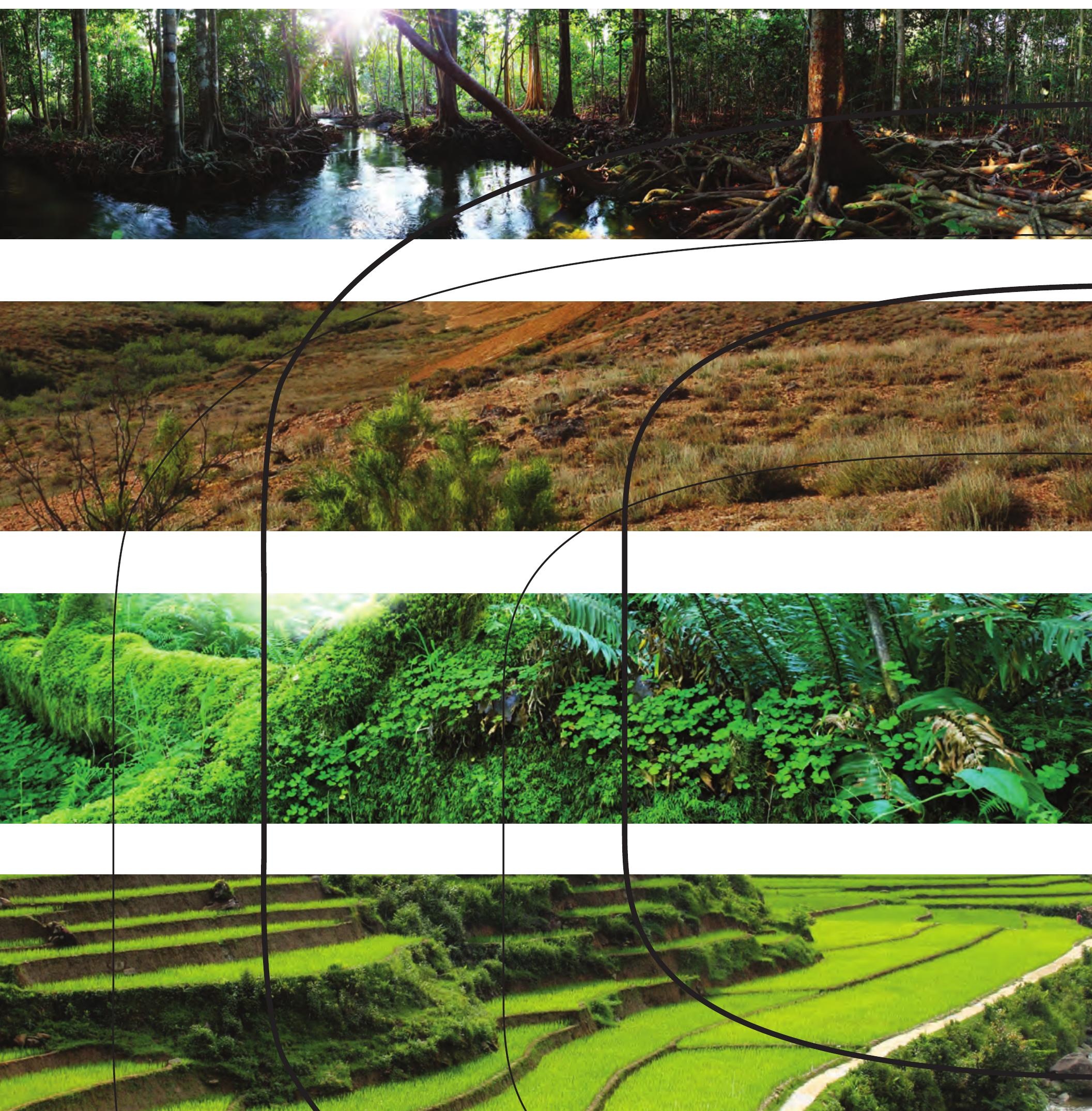

4 norden 



\section{The land-use sector within the post-2020 climate regime}

Charlie Parker, Eduard Merger, Charlotte Streck, Darragh Conway, Timm Tennigkeit and Andreas Wilkes

TemaNord 2014:520 
The land-use sector within the post-2020 climate regime

Charlie Parker, Eduard Merger, Charlotte Streck, Darragh Conway, Timm Tennigkeit and Andreas Wilkes

ISBN 978-92-893-2751-0

ISBN 978-92-893-2752-7 (EPUB)

http://dx.doi.org/10.6027/TN2014-520

TemaNord 2014:520

ISSN 0908-6692

(C) Nordic Council of Ministers 2014

Layout: Hanne Lebech

Cover photo: ImageSelect

This publication has been published with financial support by the Nordic Council of Ministers. However, the contents of this publication do not necessarily reflect the views, policies or recommendations of the Nordic Council of Ministers.

www.norden.org/en/publications

Nordic co-operation

Nordic co-operation is one of the world's most extensive forms of regional collaboration, involving Denmark, Finland, Iceland, Norway, Sweden, and the Faroe Islands, Greenland, and Åland.

Nordic co-operation has firm traditions in politics, the economy, and culture. It plays an important role in European and international collaboration, and aims at creating a strong Nordic community in a strong Europe.

Nordic co-operation seeks to safeguard Nordic and regional interests and principles in the global community. Common Nordic values help the region solidify its position as one of the world's most innovative and competitive.

\section{Nordic Council of Ministers}

Ved Stranden 18

DK-1061 Copenhagen $\mathrm{K}$

Phone (+45) 33960200

www.norden.org 


\section{Content}

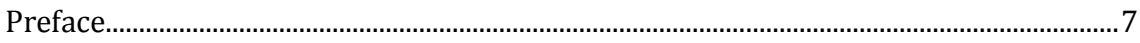

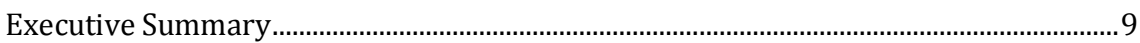

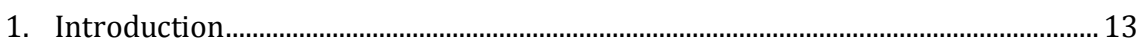

1.1 Forests, Agriculture and Climate Change...................................................... 13

1.2 Land use and the UNFCCC ................................................................................. 15

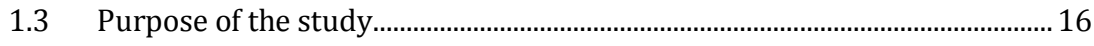

2. Overview of land use under the UNFCCC................................................................... 17

2.1 The historical division of commitments under the Convention.................... 17

2.2 Key substantive issues under the negotiations ............................................... 19

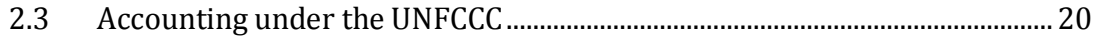

$2.4 \quad$ Measurement and Reporting............................................................................... 38

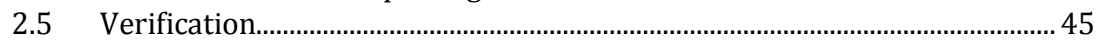

3. Options Analysis: Convergence and Synergies........................................................ 51

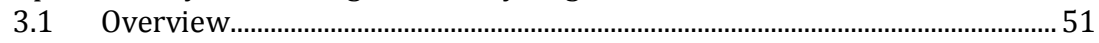

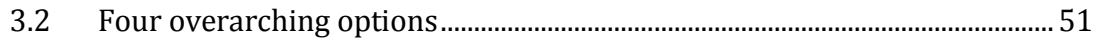

3.3 Accounting of land-use in post-2020 framework ........................................... 53

3.4 Measurement and reporting of land use in post-2020 framework............. 61

3.5 Verification of land use in post-2020 framework............................................ 64

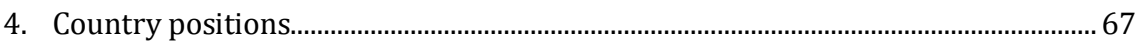

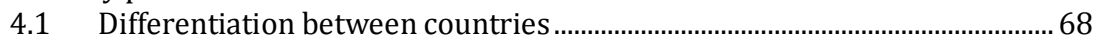

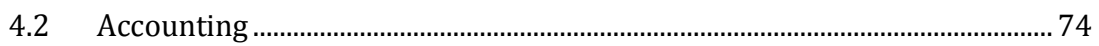

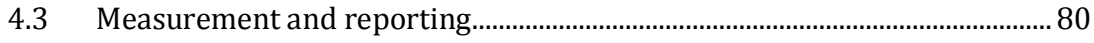

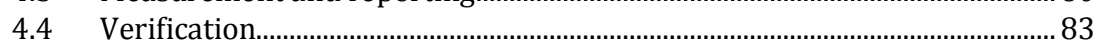

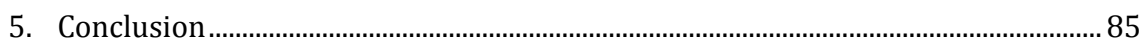

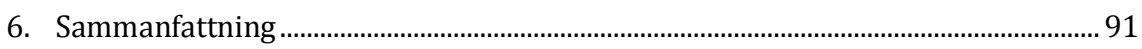

7. Annex I: List of Parties' submissions ........................................................................ 95

8. Annex 2: Land use pledges under the Copenhagen Accord ..........................................99 



\section{Preface}

Agriculture, deforestation, forest degradation and other land-use changes are significant sources of global GHG emissions. At the same time the sectors are highly vulnerable to the impacts of climate change. There exists a lot of cost-efficient mitigation potential, including potential mitigation activities such as reducing deforestation and degradation, increasing carbon stocks through different measures, substituting fossil fuels and energy-intensive materials and reducing harvest losses and food waste. Currently, the sectors are approached in a very scattered manner under the UNFCCC. Due to the complex and overlapping nature of different land uses there is a clear need for consideration on how to create a more integrated framework for the post-2020 situation, including linkages to other mitigation sectors.

This report analyses the current status of the agriculture, land-use and land-use change sectors under the United Nations Framework Convention on Climate Change and its Kyoto Protocol, and formulates options for how various incentives and systems could be harmonized under a future climate treaty. It states that a 2015 agreement will need to accommodate three key faultlines: the full coverage of land-use and land-use change emissions, the differentiation between countries according to the principle of common but differentiated responsibilities and respective capabilities and the integration of adaptation and mitigation within land-use strategies. The report further recommends that LULUCF, REDD+, agriculture and the related financial issues and incentives should be brought together and negotiated as one package. All in all, the land-use sector should be integrated to the 2015 agreement in a manner that strengthens - rather than weakens - the future climate change regime. 
Climate Focus and Unique Forestry and Land Use GmbH have carried out the study for NOAK, a working group under the Nordic Council of Ministers. The aim of NOAK is to contribute to a global and comprehensive agreement on climate change with ambitious emission reduction commitments. To this end, the group prepares reports and studies, conducts meetings and organizes conferences supporting the Nordic negotiators in the UN climate negotiations.

Helsinki April 2014

Harri Laurikka

Chair of the Nordic Working Group for

Global Climate Negotiations 


\section{Executive Summary}

The land-use sector has great potential for synergies across the objectives of climate change mitigation, adaptation, food security, energy security and poverty reduction. Agriculture, forests and other land use are responsible for $25 \%$ of global greenhouse gas (GHG) emissions, and could provide a major source of cost-effective emissions reductions and removals. The land-use sector also serves a wide variety of key environmental and social functions and supports the livelihoods of approximately half of the world's population. However, land use also raises complex trade-offs among the issues of climate change, food security, and trade. Climate change will alter agricultural production and affect food prices; which in turn will lead to changes in global trade flows. Despite these trade-offs, however, the question remains, how to find synergies between adaptation, mitigation and the land-use sector in the context of a growing global economy.

The negotiation of a future climate treaty presents an opportunity to improve the current system and create an integrated accounting and incentive framework for adaptation and mitigation strategies across all land uses. While the UN Framework Convention on Climate Change (UNFCCC) recognizes the particular role of the land-use sector in climate change mitigation and adaptation, it fails to formulate a coherent vision for the sector. In fact, the UNFCCC and its Kyoto Protocol have established a fragmented set of rules, incentives and obligations for the landuse sector, making it difficult to create consistent national strategies that consider the land-use sector as a whole rather than only through particular emission sources. Given the division of land use across dozens of separate agenda items and negotiation streams within the international climate negotiations, however, there is a risk that, without a dedicated effort, the current system of piece-meal consideration of the land-use agenda will be carried forward to a new climate treaty.

A post-2020 agreement will have a variety of different commitments and land use will figure differently within these commitments. Commitments could be in the form of economy-wide targets that either include or exclude forestry and agriculture. Commitments could also be made as sectoral commitments, similar to existing pledges to reduce deforestation. These pledges may formulate absolute or relative emission reduc- 
tion commitments. Some countries may adopt project-based mechanisms similar to the current Clean Development Mechanism (CDM) and Joint Implementation (JI). Finally, countries may commit to undertake policies and measures in the land-use sector without quantifying associated emission reductions or removals. Taking current mitigation pledges as indicators for future commitments, developing countries could show a higher variety in the nature of their post-2020 commitments than developed countries.

The overall integrity of land-use accounting depends on the integrity of its parts including the ambition of the activities and commitments that Parties put forward, as well as the integrity of the accounting, and measurement, reporting and verification (MRV) rules. Current land-use rules are fragmented and accommodate a range of Party circumstances. Considering the overall levels of uncertainty and the dynamics in international negotiations, the land-use sector may remain prone to trade-offs. Parties may continue to use the land-use sector to gain some flexibility in meeting their targets.

A post-2020 land-use agreement will need to accommodate three key faultlines: the full coverage of land-use emissions (i.e. from forests as well as agriculture); the differentiation between countries according to the principle of common but differentiated responsibilities; the integration of adaptation and mitigation within land-use strategies. In addition the system should be coherent and consistent across landscapes and countries while allowing for scaled up mitigation ambition and ensuring environmental integrity of the overall system. Within this context, the following points emerge as essential within the current negotiations of a post-2020 framework:

There should be a set of harmonized, coherent policies on land-use. Complex provisions under one negotiation stream can be much better harmonized than individually and distantly negotiated clauses in a separate and fragmented set of agreements. Land use, land-use change, and forestry (LULUCF), Reduced Emissions from Deforestation and forest Degradation (REDD+), agriculture and any dedicated clauses on finance and incentives should be brought together and negotiated as one package. Commitments within this package will differ, but the various accounting and MRV frameworks should be consistent and facilitate vertical and horizontal integration across and within countries and over time.

Move towards full accounting. Ultimately, Parties should aim for full accounting of all land-based sources and emissions. Parties with higher responsibility and capability should either move directly to full landscape accounting or provide a timetable by when full wall-to-wall ac- 
counting will be possible. Parties with less capacity and responsibility should continue to use an activity-based approach (such as REDD+) with flexibility to move to full landscape-level accounting. Such integrated systems could first be built on a sub-national basis and finally expand to cover as much of the national territory as possible (with a focus on regions with high emissions or high mitigation potential).

Consideration of different capabilities. Many developing countries lack the data, funds and capacities for land-use accounting. Countries should be supported in building the relevant capabilities and MRV rules should devise a system that encourages land-use reporting of all countries with rules creating more stringent requirements as capabilities increase. Developing countries with lower capabilities or low levels of land-use emissions can be encouraged to contribute to mitigation efforts, but should receive support with a priority to adapt to climate change.

Transparency should be encouraged, which means that incentives are set to encourage full reporting rather than encouraging countries to hold information back. Any endeavors to combine LULUCF and REDD+ accounting would need to proceed cautiously, ensuring that the current REDD+ framework is enhanced, rather than replaced, and that clear distinctions are made between the level of responsibility of developed and developing countries.

Financial incentives should be available for all land-use activities. This includes results-based payments for emission reductions from land-use activities, but also investments in carbon projects or dedicated policies and measures. Rules that allow the nesting of various accounting frameworks should be formulated and countries assisted to implement such frameworks. Rules for permanence should allow for more fungibility of land-based emissions and removals. There should be a window for the land-use sector under the Green Climate Fund (GCF), considering that the land-use sector will require special consideration, incentives and accounting frameworks.

Overall land-use should be used to strengthen rather than weaken a future climate regime. Within this system differentiation is both achievable and needed. An overall system should account for differing capabilities and the need for financial incentives. Considering these differences, integration can follow a stepwise approach. There are plentiful opportunities for incremental integration that can help to consolidate the planning process and reduce the number of fragmented tracks.

Finally, there remains a risk that the lack of political will and common understanding will lead once more to a complicated compromise with significant holes and gaps. This time, however, the differences would be 
less obvious, and the chances for success greater. Since the negotiations of the Kyoto Protocol much knowledge has been built, data collected, and confidence gained. The trench between developing and developed countries has not disappeared, but it is now crisscrossed by a complex pattern of alliances - collaborating and opposing each other depending on their particular interests, constraints, and policy priorities. As a result, Parties' individual commitments may take many different forms reflecting national circumstances and capabilities. This multitude of commitments and action would greatly benefit from an increased coherence in accounting procedures and the alignment of incentive structures. 


\section{Introduction}

\subsection{Forests, Agriculture and Climate Change}

The land-use sector has great potential for synergies across the objectives of climate change mitigation, adaptation, food security, energy security and poverty reduction. Agriculture, forests and other land use (AFOLU) are responsible for around a quarter of global GHG emissions, and provide a central opportunity for achieving cost-efficient emission reductions. ${ }^{1}$ The land-use sector is an important carbon storage reservoir; tropical forests alone store some 229 billion tonnes of carbon $(\mathrm{tC})$ in their vegetation, ${ }^{2}$ while agricultural systems store a further 1,500 billion $\mathrm{tC}$ in their soils alone. ${ }^{3}$

The land-use sector serves a wide variety of key environmental and social purposes beyond carbon sequestration. Forest's ecological functions include watershed regulation, local climate control, soil management, and they are host to some 90 per cent of the world's terrestrial species, biodiversity conservation. ${ }^{4}$ Though the land-use sector is not unique in holding links with other social and environmental concerns the energy sector, for example, is closely connected with local air pollution and poverty alleviation - the links here are more fundamental, and more complex, than elsewhere. This requires that meaningful consideration be given to non-carbon aspects of mitigation and adaptation actions in the sector in order to ensure that GHG emissions and increased resilience do not come at the expense of other important goals.

Our landscapes - forests, wetlands and agricultural lands - will be immensely affected by climate change through higher temperatures, greater crop water demand, more variable rainfall, and weather extremes. Landuse patterns therefore are highly diverse and context-specific. Adapting to

\footnotetext{
1 Tubiello, F. et al. The FAOSTAT database of greenhouse gas emissions from agriculture. 2013. Available from: http://www.fao.org/climatechange/36143-0fa4483057747f41c08183b702ec5954e.pdf 2 Baccini, A. et al. Estimated carbon dioxide emissions from tropical deforestation improved by carbon-density maps. 2012. Available from: http://www.nature.com/nclimate/journal/v2/n3/full/nclimate1354.html 3 Powlson, D., Whitmore, A., Goulding, K. Soil carbon sequestration to mitigate climate change: a critical reexamination to identify the true and the false. European Journal of Soil Science, 42-55. 2011.

${ }^{4}$ Stern, N. Stern Review: The Economics of Climate Change. Cambridge, UK: Cambridge University Press. 2006.
} 
these conditions, and in particular feeding an increasing world population in the face of the changing climate, is one of the major challenges of the coming decades. Adaptation is a pre-condition for food security and resilient agricultural systems are the basis for human survival. Meanwhile, forests and agriculture support the livelihoods of 2.6 billion people worldwide and account for 20-60 per cent of the gross domestic product of many developing countries. ${ }^{5}$ More than any other activity, the land-use sector caters to the very basic needs of people.

While the land-use sector can provide key synergies across mitigation, adaptation, food security and poverty alleviation there is also the potential, and sometimes the necessity, for trade-offs across these objectives. Agricultural production will need to grow in order to meet increased demand for food. ${ }^{6}$ In the context of a changing climate, practices and technologies that may be synergetic in one context may have significant detrimental effects in another due to differing climatic or agricultural conditions. ${ }^{7}$ At the same time, when climate change threatens food production and supply, adaptation measures become essential. Consequently, one of the most important areas in which trade-offs might occur is between mitigation and food security. Agriculture also raises complex links among the issues of climate change, food security, and trade. Climate change will likely affect agricultural production and the distribution and supply of food, which will alter food prices, in turn leading to significant changes in global trade flows. ${ }^{8}$

Despite these trade-offs, the question remains, how to find synergies between adaptation, mitigation and the land-use sector to plan for a more sustainable and food-secure future. ${ }^{9}$

\footnotetext{
${ }^{5}$ Hoffman, U. Assuring food security in developing countries under the challenges of climate change: Key trade and development issues of a fundamental transformation of agriculture. Discussion Paper No. 201, Geneva: United Nations Conference on Trade and Development. 2011.

${ }^{6}$ Streck, C. et al. Addressing Agriculture in Climate Change Negotiations: A Scoping Report. Meridian Institute. 2011. Section 1.3. Page. 4. Available from: http://www.climate-agriculture.org

7 Ibid.

8 ibid. Section 2.3. Page 5

9 Wollenberg E, et al. Setting the agenda: Climate change adaptation and mitigation for food systems in the developing world. 2012. Available at http://cgspace.cgiar.org/handle/10568/24914
} 


\subsection{Land use and the UNFCCC}

The UN Framework Convention on Climate Change (UNFCCC) recognizes the particular role of agriculture (Art. 2 and 4.1) and forestry (Art. 4.1 and 4.2) in climate change mitigation and mandates the preparation of adaptation strategies that consider the needs of the agriculture, forestry, and other land-use (AFOLU) sector (Art. 4.1 and 4.8).

Despite this emphasis on the importance of forestry and agriculture within the Convention, the climate regime fails to formulate a coherent vision or set of incentives for mitigation in the land-use sector while maintaining the ecological and social functions of our landscapes. Quite the contrary, the UNFCCC and its Kyoto Protocol sketch a fragmented set of rules, incentives and obligations. The Kyoto Protocol considers forest emissions and sinks in developed countries, but fails to create incentives for the sector's highest emission reduction (deforestation) and carbon storage (soils) potential in developing countries. Developed countries have to account for some gases, activities, and lands as part of their emission targets under the Kyoto Protocol, but significant activities and sources of emissions can be excluded. Under the Convention, developing countries are encouraged to develop agricultural mitigation programmes under the incentive framework for nationally appropriate mitigation actions (NAMAs) and/or reducing emissions from deforestation and forest degradation (REDD+); yet it is not clear whether and how these incentive frameworks would complement each other. These fragmented and, at times, overlapping reporting and accounting frameworks create concrete risks of double counting on one hand, and significant accounting gaps on the other. The various existing and emerging incentive frameworks, meanwhile, make it difficult to create consistent national strategies that consider the land-use sector as a whole rather than only through particular emission sources.

The negotiation of a future climate treaty presents an opportunity to improve the current system and create an integrated accounting and incentive framework that facilitates the formulation of robust and complementary adaptation and mitigation strategies across all land uses. Given the division of land use across dozens of separate agenda items and negotiation streams within the international climate negotiations, however, there is a risk that without a dedicated effort the current system of piece-meal consideration of the land-use agenda will be carried forward to a new climate treaty. 


\subsection{Purpose of the study}

Within this context, the overall objective of this study is:

- To describe the current treatment of the land-use sector under the UNFCCC and the Kyoto Protocol.

- To discuss options on how various incentives and systems can complement each other under a future climate treaty.

- The paper also aims to demystify and improve an understanding of key issues within negotiation under the Convention.

The intended audience is broad and includes negotiators of land use under a future climate agreement, as well as observers interested in the role of land use in climate change mitigation and adaption.

This paper begins in Section 2 with a description of the current treatment of land use under the UNFCCC and the Kyoto Protocol by looking at the main substantive areas of negotiations under the UNFCCC, namely accounting, measurement and reporting, and verification. Section 2 explores and compares the fragmented landscape of mechanisms set out by the Convention and its Kyoto Protocol, including the treatment of land use under the Protocol's "flexible mechanisms" and the emerging regimes addressing agriculture and forestry in developing countries. It goes on to consider recent developments in broadening the consideration of land use, namely the recent reforms to the Protocol's land-use rules and the emerging regimes addressing agriculture and forestry including REDD+.

Building on this landscape, Section 3 considers options for consolidating the various mechanisms in the context of a future climate treaty, taking into account the current lines of convergence and divergence across the major faultlines of the Convention; i.e. the current divisions between mitigation and adaptation, agriculture and forestry, and developed and developing countries. Section 4 then looks at the political dimensions of a future climate change treaty and the feasibility of different options given the different views and circumstances of Parties to the Convention. This study concludes in Section 5 by offering some final thoughts on the way forward for the sector under a future regime including possible outcomes that may be achieved in Paris under the Durban Platform and elements of a roadmap towards a future 2020 agreement. 


\section{Overview of land use under the UNFCCC}

\subsection{The historical division of commitments under the Convention}

The Convention divides countries into two overarching groups according to their differing commitments and responsibilities:

- Annex I Parties include the industrialized countries that were members of the Organisation for Economic Co-operation and Development (OECD) in 1992, plus countries with economies in transition (EIT), including the Russian Federation, and several other Baltic, Central and Eastern European States.

- Non-Annex I Parties are the remaining countries that are mostly comprised of developing countries. Certain countries are recognized as being especially vulnerable to the adverse impacts of climate change and the 49 Parties classified as least developed countries (LDCs) by the United Nations are given special consideration under the Convention.

In addition, Article 3.1 of the Convention states that:

\footnotetext{
"Parties should protect the climate system ... in accordance with their common but differentiated responsibilities and respective capabilities. Accordingly, the developed country Parties should take the lead in combating climate change and the adverse effects thereof."
}

This statement of "common but differentiated responsibilities and respective capabilities" (CbDR and $\mathrm{RC}$ ) created a division in both the expectations (i.e. the level of commitment taken by Parties) as well as the mechanisms that are available to Parties under the Convention. 
Under the Kyoto Protocol and its subsequent Marrakesh Accords, the majority of Annex I Parties (listed in Annex B of the Kyoto Protocol) ${ }^{10}$ have taken on legally binding emissions targets, known as quantified emission limitation or reduction commitments (QELRCs). Annex B Parties may achieve their commitments either by undertaking domestic policies and measures that reduce GHG emissions, or by purchasing emissions reductions through the "flexible mechanisms".11 With respect to land use, detailed guidelines were laid out under the Marrakesh Accords for how developed countries should address domestic emissions reductions and removals from land use, land-use change, and forestry (LULUCF). ${ }^{12}$

Non-Annex I Parties on the other hand were urged to develop domestic mitigation and adaptation measures with the expectation that Annex II Parties would finance these. ${ }^{13}$ Non-Annex I Parties could additionally participate in domestic mitigation options through the Clean Development Mechanism (CDM). Because of concerns over leakage and permanence, however, land-use accounting rules under the CDM were complex and ultimately excluded from the EU emissions trading system, effectively closing the door on the CDM as a source of mitigation finance for developing countries.

While the Bali Action Plan, under its ad hoc working group on longterm cooperative action (AWG-LCA) aimed to break down this firewall between developed and developing countries, this division has remained consistent throughout these negotiations and mechanisms are still highly differentiated between developed and developing countries. Under the Copenhagen Accord, Annex I Parties committed to implement economy-wide emissions targets for 2020, which were specified in Appendix I to the Accord. Non-Annex I Parties were also requested to implement nationally appropriate mitigation actions (NAMAs) listed in Appendix II of the Accord.

Under a post-2020 framework it is expected that the binary system of the Kyoto Protocol will be broken down and there will be a more "graduated" approach between developed and developing country Parties. It

\footnotetext{
${ }^{10}$ Emissions targets are outlined in Annex B of the Kyoto Protocol. With only two exceptions, these Parties are equivalent to Annex I Parties of the Convention. The U.S. is listed in Annex B with an emissions target but did not ratify the Kyoto Protocol. Other Parties including Japan and NZ did not ratify the second commitment period of the Kyoto Protocol.

${ }^{11}$ FCCC/CP/2001/13/Add.1.

12 Decision 11/CP.7.

${ }^{13}$ Annex II Parties are a subset of Annex I excluding EITs that are required to provide financial resources to enable developing country Parties to climate change mitigation and adaptation activities.
} 
is within this context that Section 3 explores options for a more streamlined land-use framework.

\subsection{Key substantive issues under the negotiations}

Negotiations on land use can be grouped into three broad substantive issues:

- Accounting: The decision of what "counts" under the Convention is fundamental in developing a mitigation framework under the landuse sector. Art. 7 of the Kyoto Protocol establishes annual GHG inventories for Annex I Parties as a means to achieve their commitments under Art. 3.1. Accounting rules essentially define how emissions reductions and removals can be generated and therefore how a Party can achieve its mitigation target or commitment. As such, accounting rules are also important in defining the types of incentives a Party might have in taking on land-use mitigation activities. Second order accounting questions include: What types of activities are eligible towards mitigation targets? What benchmark will be used to determine emissions reductions or removals? How will permanence and leakage be addressed? How will emissions reductions be tracked?

- Measurement and Reporting: Secondary to the question of accounting is how emissions and removals will be measured and reported. Measurement and reporting decisions are essential to ensure the final system is transparent (including reporting of uncertainties), consistent (over time), comparable (across countries), complete (i.e. the data and information supports technical analysis of the results) and accurate (i.e. uncertainties are minimized) in land-use frameworks. Additional considerations for measurement and reporting include: What is the periodicity of reporting? What pools and gases are included? Is reporting land-based or activity-based? What level of uncertainty is allowed?

- Verification: Verification is an essential process to ensure that (often self-reported) data meets the requirements laid out in accounting rules. The Intergovernmental Panel on Climate Change (IPCC) refers to verification as "activities and procedures that can be followed 
during the planning and development, or after completion of an inventory that can help to establish its reliability for the intended applications of that inventory." 14 Common considerations for verification include: How often is verification required? Who will undertake the verification?

The remainder of this section explores the current framework for land use under the Convention and is broken down across these three substantive issues.

\subsection{Accounting under the UNFCCC}

Accounting rules are the starting point in understanding how land use is treated under the Convention; these rules determine what "counts" and ultimately how emissions reductions and removals can be generated and therefore how a Party can achieve its mitigation target or commitment. To a large extent, accounting rules also determine what systems are needed to measure, report and verify emissions and removals, and the level of rigor needed in these systems.

Following the lines established under the Convention between developed and developing country Parties, accounting rules for land use are divided into two broad categories. Annex I Parties are subject to rules defined under the negotiations on land use, land-use change and forestry (LULUCF) and agriculture under the Kyoto Protocol. Non-Annex I Parties on the other hand can participate either in project-based activities in accordance with modalities defined under the CDM or more recently through rules and procedures defined under the negotiations on reducing emissions from deforestation and forest degradation (REDD+).

Accounting rules as outlined in Table 1 need to fulfill the following basic criteria:

- Eligible activities: Is accounting land-based or activity-based? If activity-based accounting is used, which activities are voluntary and which are mandatory?

14 IPCC (2003). Good Practice Guidance for Land Use, Land-Use Change and Forestry. Kanagawa, Japan, IPCC National Greenhouse Gas Inventories Programme and Institute for Global Environmental Strategies (IGES). 
- Contribution to national GHG targets: To what extent do emissions reductions or removals from the land-use sector contribute to national targets?

- Baseline: How are emissions reductions generated, i.e. below a base year, or using a reference level? Are emissions accounted using gross-net or net-net accounting?

- Non-permanence: How is non-permanence addressed and what units will be generated from land-use activities (such as tCERs and RMUs). Is there fungibility between emissions reductions from the land-use and other sectors?

- Tracking Mechanism: How are credits or allowances recorded and tracked? This is relevant both for domestically generated as well as internationally traded emissions reductions and removals.

Using these five criteria the following section describes the current legislation for land use under the UNFCCC. The section is divided into accounting rules for Annex I Parties, the Kyoto Mechanisms, i.e. CDM and Joint Implementation (JI) and accounting rules for Non-Annex I Parties.

\subsubsection{Land-use accounting for Annex I Parties to the Convention}

The Kyoto Protocol requires Annex I Parties to implement policies and measures that promote sustainable forest management (SFM), afforestation and reforestation $(\mathrm{A} / \mathrm{R})$ as well as sustainable forms of agriculture to achieve their emission reductions and limitation targets. ${ }^{15}$ The Kyoto Protocol also calls for the mandatory accounting of a limited number of land-use activities (namely afforestation, reforestation and deforestation since 1990), ${ }^{16}$ and the identification by the first session of the Conference of the Parties to the UNFCCC (COP) serving as meeting of the Parties to the Kyoto Protocol (CMP 1) of other activities that might be included voluntarily towards national commitments, as well as a number of basic accounting rules.

The call for sustainable land-use policies was uncontroversial in the negotiations that led to the Kyoto Protocol. Far more contentious, however, was the calculation and treatment of land-use emissions and their

${ }^{15}$ Kyoto Protocol Art. 2.1.a (ii) and (iii).

16 Kyoto Protocol Art. 3.3. 
contributions to national mitigation commitments. Specifically, the decision on whether to include LULUCF emissions within Annex I baseline emissions and to what extent they would count towards national commitments was controversial as it could dramatically alter the scope and stringency of Parties' targets. Due to these concerns, further details, including those with profound effects on mitigation targets, were left to subsequent decisions by the CMP which, following further contentions negotiations, were finalized only in 2006 several years after rules for other sectors. ${ }^{17}$

The resulting decisions on LULUCF, which attempted to cover the concerns and national circumstances of a wide range of Parties, are consequently very elaborate, fragmented and, ultimately, reflect substantial compromises. The rules provide Parties with significant flexibility in a range of areas, most notably in choosing which activities to include, and through optional accounting of net emissions in 1990 (the so-called "Australia clause"). These flexibilities seek to accommodate a variety of party-specific concerns and arguably weaken the mitigation commitments assumed under the Kyoto Protocol, a danger inherent in negotiating such rules only after commitments have been agreed. 18

At CMP7 in Durban in 2012, Parties agreed on a revised set of rules to be applied to land-use accounting under the Kyoto Protocol's second commitment period. ${ }^{19}$ In contrast with the first commitment period, the new rules were agreed in parallel with Parties' mitigation commitments for the second period, hence enabling an integrated discussion of the level of targets and the rules influencing the effort required for their achievement. ${ }^{20}$

The remainder of this section lays out the key decisions on land-use accounting for Annex I Parties. These decisions are also summarized in Table 1 below.

\section{Eligible activities for accounting}

While the Convention includes all emissions and removals from LULUCF, the Kyoto Protocol restricts accounting of emissions and removals to specific "direct, human-induced" activities that are defined under Article 3, paragraphs 3 and 4, of the Kyoto Protocol. In other words, Parties can pick

\footnotetext{
17 The negotiations on LULUCF were concluded at COP9 in Nairobi and formally adopted by the COP/MOP in Montreal: Decision 11/CMP.1; Decision 13/CMP.1; Decision 15/CMP.1; Decision 16/CMP.1.

18 Niklas Höhne et al., "The rules for land-use, land-use change and forestry under the Kyoto Protocol -

lessons learned for the future climate negotiations" 10 Environmental Science and Policy 353 (2007) 367.

19 Decision 2/CMP.7, Annex I.

${ }^{20}$ Andrew Prag, Christina Hood and Pedro Martins Barata, 43.
} 
and choose which activities they include or exclude toward their national target, and non-anthropogenic changes (i.e. fires, pests, and other nonhuman-induced changes in forest cover) are not accounted for.

Under Article 3.3 of the Kyoto Protocol, accounting for emissions and removals from afforestation, reforestation and deforestation (ARD) is mandatory, whereas under Article 3.4 accounting for forest management, cropland management, grazing land management and revegetation is voluntary. ${ }^{21}$ The most significant change for the second commitment of the Kyoto Protocol period relates to forest management. Accounting for forest management is now mandatory and includes harvested wood products (HWP), putting to a closure discussions on accounting for carbon stored in wood products that have been ongoing since 1999.22 Wetland drainage and rewetting was included as a further optional activity for accounting. To ensure that any subsequent changes in emissions or removals are accounted for, optional activities once included in national accounts must continue in subsequent commitment periods. ${ }^{23}$

Agricultural emissions are largely treated independently from LULUCF emissions under the Kyoto Protocol leading to further fragmentation in land-use accounting. Emissions resulting from land management are covered under voluntary accounting rules for LULUCF, i.e. cropland management, grazing land management and revegetation. Emissions resulting from the industrial processes that support agriculture (nitrous oxide from fertilizer production and use) and livestock (methane) on the other hand are not considered under the LULUCF rules and fall into the mandatory emissions accounting of industrial emissions.

\section{Contribution to national GHG targets}

As with other sectors under the Protocol, LULUCF emissions and removals may be used towards national targets of developed countries. In contrast to emissions from other sources, the Kyoto Protocol requires Parties to account for emissions and removals from LULUCF activities by adding to or subtracting from their initial assigned amount. Net removals from LULUCF activities result in the issuance of removal units (RMUs), which a Party may add to its assigned amount; net emissions from LULUCF activities are accounted for by cancelling Kyoto units. RMUs are, for the most

\footnotetext{
${ }^{21}$ As initially outlined under Kyoto Protocol Art. 3.4 and further elaborated in the Annex to Decision 16/CMP.1.

22 SBSTA 11 - FCCC/SBSTA/1999/14

${ }^{23}$ Annex to Decision 16/CMP.1.
} 
part, equal to Assigned Amount Units (AAUs), although they may not be carried forward to the second commitment period. ${ }^{24}$

Given concerns over the stringency of accounting rules for LULUCF, as well as the permanence of land-use emissions reductions and removals, the use of RMUs is subject to "caps" under developed countries targets, limiting the extent to which Parties can use LULUCF emissions reductions and removals towards national targets. These caps vary by activity for domestically generated emissions as outlined below: 25

\section{Afforestation and reforestation}

Under LULUCF accounting rules, afforestation and reforestation (AR) activities can only be accounted as a net sink. ${ }^{26}$ This rule has two implications for accounting rules under AR. ${ }^{27}$ First, "accounting quantities" should be calculated separately for harvested land versus non-harvested land, ${ }^{28}$ given that the above rule applies only to harvested land. Second, accounting quantities must be calculated for individual units of land rather than aggregated GHG emissions and removals from all units of harvested land, i.e. a Party cannot cancel emissions from one area with removals from another. This also implies a certain level of precision in Parties' measurement and reporting requirements (see below).

\section{Deforestation}

The calculation of emissions from deforestation is simpler. A party simply sums net emissions or removals from all deforested land areas during the accounting period. As with the AR activities, only direct, humaninduced deforestation needs to be accounted for.

\section{Forest management}

Two accounting rules apply to forest management: the "offset rule" and the forest management cap or "FM cap". Under the offset rule, if a Party's accounting of mandatory LULUCF emissions (i.e. those from ARD in the first commitment period) results in a net source of emissions, these can be offset through FM activities. The quantity of RMUs that a Party may

\footnotetext{
24 Decision 13/CMP.1, paragraph 16.

${ }^{25}$ LULUCF emissions reductions and removals generated through the flexible mechanisms are also capped at a fixed annual amount (see Section 2.3.2).

26 Decision 16/CMP.1, Annex, paragraph 4.

27 Kyoto Protocol Reference Manual on accounting of emissions and assigned amount.

http://unfccc.int/resource/docs/publications/08_unfccc_Kyoto Protocol_ref_manual.pdf

28 The term accounting quantities is adopted from the Kyoto Protocol Reference Manual to refer to quantities

of emissions reductions or removals that can count towards a national target.
} 
issue to offset these activities is capped at $165 \mathrm{Mt} \mathrm{CO2e}$ or the net source of emissions (whichever is greater) for the first commitment period. ${ }^{29}$ Under the second commitment period the offset rule was discontinued and replaced by forest management reference levels (see below).

Under the FM cap rule, Parties are subject to a country-specific cap on the additions to and removals from its assigned amount resulting from forest management activities. ${ }^{30}$ The FM cap rule also changed under the second commitment period. The country-specific limits that determine the quantity of forest management allowances that can be issued in each year of the commitment period have been replaced with a uniform limit of $3.5 \%$ of base year emissions per year. The cap also now only applies to additions, with no limit on subtractions from assigned amounts.

\section{Harvested wood products}

Under the second commitment period it was agreed that Annex I Parties must account for Harvested wood products (HWP) emissions in their national accounts. ${ }^{31}$ Under these revisions, the accounting of HWP can be on the basis of instantaneous oxidation or using a decay function that assumes a certain level of emissions over the lifecycle of the HWP. ${ }^{32}$ While the primary goal of the HWP decision is to account for emissions that occur from harvesting in the second commitment period, emissions from harvested wood products removed from forests prior to the start of the second commitment period should also be accounted for. ${ }^{33}$

\footnotetext{
${ }^{29}$ Equivalent to $9.0 \mathrm{MtC}$ per year multiplied by five, converted to CO2e as outlined in Annex to Decision 16/CMP.1 paragraph 10.

30 Outlined in Decision 16/CMP.1, annex, paragraph 11 and its Appendix.

31 Decision 2/CMP.7, Annex, paragraph 26.

32 According to Decision 2/CMP.7, Annex, paragraph 29, these decay functions should follow the 2003 IPCC guidelines and 2006 GPG for decay functions and default half lives.

33 Decision 2/CMP.7, Annex, paragraph 16 and 29.
} 


\section{Baseline}

Among the more contentious rule choices under LULUCF was whether to measure net human-induced land-use emissions in absolute terms or relative to a base year. This issue is substantially more complex in LULUCF that in other sectors due to three key factors:

- LULUCF emissions and removals occur across long timeframes. Emissions occurring in a given accounting period may be the result of activities that occur over decadal long timeframes; accounting for removals and emissions under a given accounting period would not reflect longer term land-use policies and measures.

- The land-use sector can be both a sink and a source. Unlike other sectors the land sector can be a net carbon sink. Accounting rules that include all emissions and removals - while reflecting what the atmosphere sees - may reward activities that are not additional.

- Not all emissions in the land-use sector are anthropogenic. The relationship between human-induced and non-human induced emissions or removals is sometimes complex and care needs to be taken to ensure that Parties are not overly rewarded or penalized for activities that are not a part of the anthropogenic system.

The negotiated rules ultimately agreed that for the Kyoto Protocol's first commitment period Parties could use a combination of both approaches: accounting for grassland management, revegetation and cropland management are subject to a "net-net" approach that compares net emissions in the accounting period to net emissions in the reference year. Emissions from ARD and FM, meanwhile, are subject to a "gross-net" approach that measures changes in carbon stocks during the commitment period without referring to a reference year. ${ }^{34}$

Under the Kyoto Protocol's second commitment period, accounting for FM will move from gross-net accounting to the use of Forest Management Reference Levels (FMRLs). FMRLs aim to reflect counterfactual scenarios based on a combination of historical figures and projected trends. The COP has approved individual FMRLs for each Party following Party proposals reviewed by expert review teams. 35 The use of FMRLs provides a flexible approach that is adaptable to country circumstances, while reduc-

${ }^{34}$ Annex to Decision 16/CMP.1.

35 Decision 2/CMP.6, Appendix II. 
ing the risk that Parties are credited for emissions reductions and removals that are not considered additional. At the same time, however, without a full, independent assessment of the approaches and assumptions used in developing FMRLs, future emission scenarios are prone to significant variations and may not reflect the true business-as-usual (BAU) scenario of a country. The review of FMRLs under the Kyoto Protocol was on technical and methodological aspects only, and did not aim to undertake an assessment of the overall foundation of FMRLs provided.

In addition to the above activity-specific baseline considerations, Kyoto Protocol Art. 3.7 allows countries with net emissions in the land-use sector in 1990 to include these emissions in the calculation of their assigned amount. ${ }^{36}$ While a range of countries meet the criteria of having net emissions from LULUCF in 1990, ultimately Australia was the only Party to benefit from this clause (leading to the naming of Art. 3.7 as the "Australia clause"). Using this allowance allowed Australia to inflate its base year emissions, effectively converting Australia's 108\% target into the equivalent of a $142 \%$ increase on 1990 levels using the standard accounting rules. ${ }^{37}$ The second commitment period will continue this clause, and again Australia will benefit from this net baseline. 38

All agricultural emissions $\left(\mathrm{CH}_{4}\right.$ and $\left.\mathrm{N}_{2} \mathrm{O}\right)$, given that they are reported under Annex A sources, ${ }^{39}$ are accounted for under a Parties' baseline emissions and would be considered net-net accounting.

\section{Non-permanence}

The Kyoto Protocol does not include any provision to ensure the permanence of emission reductions and removals achieved in the first commitment period. Aside from the fact that RMUs cannot be carried over to subsequent reporting periods, the Kyoto Protocol treats emissions reductions from land-use equally to other sectors. ${ }^{40}$ Regarding the treatment of reversals, under the second commitment period, Annex B Parties have the option to exclude emissions from natural disturbances that are not "mate-

\footnotetext{
36 Kyoto Protocol Art. 3.7.

37 A. Macintosh, LULUCF offsets and Australia's 2020 abatement task. ANU Center for Law and Policy. http://law.anu.edu.au/sites/all/files/coast/lulucfoffsets_17_feb_2011.pdf (accessed 4th August 2013). 38 Decision 1/CMP.7, Annex 3 B.

${ }^{39}$ Annex A to the Kyoto Protocol covers GHG emissions from the energy, industrial processes, solvent and other product use, agriculture and waste sectors). Art 3.1 of the Kyoto Protocol requires Annex I Parties to ensure that its total emissions from GHG sources listed in Annex A to the Kyoto Protocol do not exceed its allowable level of emissions.

${ }^{40}$ Given Australia's application of Art. 3.7, emissions reductions arising from the net accounting of emissions under the first commitment period could be carried over to the second commitment period.
} 
rially influenced" by the Party. A default method to estimate the background level is provided, above a country-specific "background level" for afforestation, reforestation and forest management, but countries may also apply an alternative approach as long as transparency, consistency and comparability are ensured, and net credits are avoided.

\section{Tracking Mechanism}

Each Annex I Party is required to establish and implement an electronic database, called a national registry, to track issuance, holdings, transactions and carry-over of Kyoto units. Each registry must conform to detailed technical standards that cover data format, data exchange and communication between registries, data security, serial numbers of Kyoto units and transaction rules, including termination of invalid transactions. ${ }^{41}$

The secretariat also established an international transaction log (ITL) to verify transactions of Kyoto units by national registries and the CDM registry. 42 Whenever a registry undertakes a transaction it communicates with the ITL, which checks if the transaction conforms to the general rules for accounting of the assigned amount, as well as with the specific rules for the particular mechanism and transaction in question. The ITL also receives information from the CDM information system regarding CDM projects and the JI information system regarding ERUs verified under JI Track 2 procedures (see below).

\subsubsection{Land-use accounting under the Kyoto Mechanisms}

In addition to allowing Annex B Parties to develop domestic policies and measures to mitigate climate change, the Kyoto Protocol provides developed country Parties with three "flexible mechanisms" to meet their QELRCs. These Kyoto mechanisms are:

- International Emissions Trading between countries with targets (Art. 17 Kyoto Protocol).43

- The CDM which allows Annex B countries to acquire GHG emission reductions from projects in developing countries (Art. 12 Kyoto Protocol).44

\footnotetext{
${ }^{41}$ Decision 13/CMP.1, Annex, paragraphs 17-22.

42 Decision 13/CMP.1, Annex, paragraphs 38, 41, 42 and 43.

43 Kyoto Protocol Art.17.

${ }^{44}$ Kyoto Protocol Art. 12.
} 
- JI a project-based mechanism between Annex B countries (Art. 6 Kyoto Protocol). 45

The resulting emission reductions are monitored, and then transferred to the investor country (or private entity) as Emission Reduction Units (ERUs), issued under JI, or Certified Emission Reductions (CERs), issued under the CDM. ERUs are converted from existing AAUs and RMUs before being transferred. JI therefore does not affect the total assigned amount of Annex I Parties collectively; rather it redistributes the assigned amount among them.

\section{Eligible activities}

Since JI operates only within Annex B countries, with emission reduction commitments, the inclusion of LULUCF thereunder did not raise major concerns among Parties. Consequently, all LULUCF activities were determined to be eligible under JI and general accounting rules were applied. In the years following the entry into force of the Kyoto Protocol, however, a number of technical problems became obvious and acted as strong deterrents for any JI LULUCF activities. ${ }^{46}$ The most important of such problems was that only RMUs (but not AAUs) can be converted into ERUs in the context of JI LULUCF projects. In substance that means that no ERUs can be issued for emission reductions but only for carbon removal activities in developed countries. Furthermore, since most countries only elected to account for RMUs at the end of the Kyoto Protocol commitment period, ERUs from JI projects implemented in those countries will only be issued in 2014 or 2015. The deferred issuance of credits increases the risks of project investors and severely reduces the financial incentive that comes with generating emission reductions.

In contrast, the inclusion of LULUCF activities under the CDM was very controversial from the start. The controversy arose largely out of the nature of the CDM as an offset mechanism. Parties ultimately agreed only to permit afforestation and reforestation activities under the mechanism..$^{47}$ This way the risk of flooding the market in carbon credits from avoided deforestation projects was adverted, albeit at the cost of not

\footnotetext{
45 Kyoto Protocol Art. 6.

46 Bernhard Schlamadinger, Charlotte Streck, Robert O'Sullivan (2007), Will Joint Implementation LULUCF projects be impossible in practice? http://www.climatefocus.com/documents/files/will_joint_implementation lulucf_projects_be_impossible_in_practice__.pdf. Published in Point Carbon on 24th January 2007. ${ }_{47}$ Decision 19/CP.9.
} 
defining any incentives for reduced tropical deforestation. The exclusion of the overall use of CDM forestry credits under the EU Emissions Trading Scheme (ETS) further forestalled an oversupply of allegedly cheap carbon credits from forestry projects.

\section{Contribution to national GHG targets}

Under the first commitment period, emissions reductions generated through AR activities under the CDM are limited to one per cent of base year emissions of that Party, times five (i.e. one per cent for each year of the commitment period). ${ }^{48}$ During the second commitment period, Parties agreed that these rules should be continued mutatis mutandis. ERUs traded under JI are not subject to any caps on contribution to national targets.

Both flexible mechanisms to date, however, have been limited in scope, due to the range of eligible activities (under the CDM), accounting rules (under both the CDM and JI) and domestic restrictions of Annex B Parties; these caps have therefore not had any meaningful impact on the supply of credits through project-based mechanisms.

\section{Baseline}

Baselines under both JI and the CDM are created on a project-by-project basis and are defined as "the scenario that reasonably represents the anthropogenic emissions by sources of greenhouse gases that would occur in the absence of the proposed project activity." 49 Beyond this, however, the approaches and methodologies adopted under each of these mechanisms vary considerably; in general the CDM follows a stricter set of guidelines for the establishment of baselines.

Under JI, baselines can be established on a project-specific basis and/or using a multi-project emission factor. They must take into account the project boundary and in particular must account for decreases in activity levels outside the project activity or due to force majeure, and participants must justify their choice of baseline. ${ }^{50}$ Guidelines for baselines are reviewed and revised by the Joint Implementation Supervisory Committee (JISC), for consideration by the CMP, giving consideration to relevant work of the Executive Board of the CDM, as appropriate. ${ }^{51} \mathrm{JI}$ projects can also use appropriate methodologies defined under the CDM

\footnotetext{
${ }^{48}$ Annex to Decision 16/CMP.1 paragraph 14.

${ }^{49}$ Decision 9/CMP.1, Appendix B (JI), and Decision 3/CMP.1, Annex I, paragraph 44 (CDM).

${ }^{50}$ Decision 9/CMP.1, Appendix B, paragraphs 1, 2 and 3.

51 Decision 9/CMP.1, Annex, paragraph 3 (d).
} 
to set project baselines. ${ }^{52}$ The JISC in 2011 released revised guidance on criteria for baseline setting and monitoring. 53

Baselines under the CDM can follow a variety of approaches including historical, projected, and standardized baselines. ${ }^{54}$ CDM baselines are similarly developed by project participants and are reviewed by the Executive Board (EB) of the CDM. ${ }^{55}$

Projects developed under the CDM and - to a lesser extent JI - also need to demonstrate that they create "additional" emission reductions. While the Kyoto Protocol defines additionality simply as "anthropogenic emissions of greenhouse gases by sources are reduced below those that would have occurred in the absence of the registered CDM project activi$t y$,"56 the CDM EB ultimately developed a far more complex tool for the demonstration and assessment of additionality. ${ }^{57}$ The tool provides a step-wise approach to demonstrate and assess the additionality of a CDM project activity. Although the CDM additionality tool is not mandatory in its application, if it is used within a methodology it must be applied in subsequent project activities.

\section{Non-permanence}

The CDM created a very elaborate approach to addressing permanence through the creation of two types of credits: temporary credits (tCERs) and long-term credits (lCERs). The choice of which approach to adopt is left to the project developers. ${ }^{58}$ tCERs are valid for five years and may be replaced upon the certification that carbon stocks equivalent to all issued credits remain on the land. ICERs remain valid for the lifetime of the project, but must be immediately (within one month) replaced where periodic certification finds that the carbon stocks they represent no longer exist. The effect of both types of credits is similar - in each case parties must ultimately replace the credits once the project finishes, and thus only "rent" compliance..$^{59}$ Equally, this temporary nature affects

\footnotetext{
52 Decision 10/CMP.1, paragraph 4 (a) and (b).

${ }^{53}$ Available at https://ji.unfccc.int/Ref/Documents/Baseline_setting_and_monitoring.pdf

54 Decision 3/CMP.1, Annex, paragraphs 46 and 48 (a) (c).

55 Decision 3/CMP.1, Annex, paragraphs 5 and 45.

56 Decision 3/CMP.1, Annex, paragraph 43.

${ }^{57}$ Available at http://cdm.unfccc.int/methodologies/PAmethodologies/tools/am-tool-01-v7.0.0.pdf and http://cdm.unfccc.int/methodologies/ARmethodologies/tools/ar-am-tool-01-v2.pdf

58 Decision 5/CMP.1.

${ }^{59}$ Streck and Scholz, 2006, The role of forests in global climate change: whence we come and where we go.

Foreign Policy. 868.
} 
their value, making them ultimately less desirable than credits from other project types.

\section{Tracking Mechanism}

The CDM registry, administered by the Secretariat under the guidance of the CDM Executive Board, is responsible for issuing CERs upon instruction by the Executive Board and distributing them to the accounts of project participants in Annex I Party national registries. The CDM registry must conform to the same technical standards as national registries and the ITL (see above). ERUs generated by JI projects are issued by the conversion of RMUs within the registries of the project host countries.

\subsubsection{Land-use accounting for Non-Annex I Parties to the Convention}

The main decisions on land-use accounting under the UNFCCC for developing countries has been through the emergence of the policy framework known as REDD+. The ongoing negotiations on agriculture for Non-Annex I Parties are highly politicized and have stalled due to a continued difference in views among Parties (see Box 1 below).

REDD+ emerged from a proposal by Papua New Guinea and Costa Rica at COP11 in 2005 to explore options for creating incentives to avoid deforestation in developing countries, and thus fill the major gap left by the Kyoto Protocol. The proposal to avoid or slow deforestation was welcomed by the global community as one of the first internationally publicized efforts of developing countries to make a quantifiable contribution to scaled-up mitigation efforts under the Convention. This process resulted in the inclusion of tropical deforestation as one of the elements of the 2007 Bali Action Plan. 


\section{Box 1 - Agriculture and Non-Annex Parties to the Convention}

Despite the explicit mentioning of the need to address sector-specific emissions in Article 4(1)(c) of the Convention, the Kyoto Protocol did not single out any sectoral action. The Bali Action Plan changed this when it introduced sectorspecific approaches within the post-2012 negotiating framework. ${ }^{60}$ From 2010 to 2012, agriculture was negotiated under the agenda item "cooperative sectoral approaches and sector-specific actions" in the context of the Ad-Hoc Working Group on Long-Term Cooperative Action (AWG-LCA). For the first time agriculture was discussed as a sector that required special attention.

Following Bali, agriculture was considered under the AWG-LCA negotiating stream, under which a dedicated drafting group on agriculture was established in 2009. Building on a technical paper outlining opportunities in agriculture prepared by the UNFCCC Secretariat, the drafting group prepared draft text in 2009 proposing the establishment of a work programme on agriculture. However, negotiations were wracked by the unfortunate coupling of agriculture with negotiation text about bunker fuels and to disagreement on trade-related issues. An agreement could be not reached on this text before the AWG-LCA was dissolved in 2012. The discussion of agriculture following COP17 has been delegated to the less politically charged negotiations under SBSTA, which has remained unable to agree on the adoption of a work program. ${ }^{61}$

Two key disagreements underlie the lack of progress in agriculture negotiations. The first is the extent to which any work programme should be framed within the principle of common but differentiated responsibilities (CBDR). ${ }^{62}$ This carries special significance given the current negotiation of the content and scope of CBDR, ${ }^{63}$ and also reflects other sectoral negotiations, most notably those on aviation and maritime emissions. Secondly, Parties differ over the scope of a work program, and in particular whether it should include only adaptation or also mitigation and co-benefits. Several Parties are concerned that the inclusion of mitigation may lead to mitigation commitments in agriculture thereby threatening the sovereignty over a country's food security and leading to climate-motivated trade measures.

\footnotetext{
60 Decision 1/CP.17, paragraph 1 (b)(iv).

61 Decision 2/CP.17, paragraph 75.

62 Sam Bickersteth, OPINION: The current climate of agriculture in the UNFCCC, available http://cdkn.org/2013/04/the-current-climate-of-agriculture-in-the-unfccc/

63 Under the decision Parties agreed that the new agreement would be "applicable to all parties" (paragraph 2) and agreed to "close the ambition gap with a view to ensuring the highest possible mitigation efforts by all Parties" (paragraph 7). Decision 1/CP.17.
} 
The in-session workshop on agriculture at COP 19 in Warsaw aimed to provide an unprecedented opportunity for developing countries to build an open dialogue on the agriculture sector under the UNFCCC. The workshop agenda included consideration of the possible roles of all the relevant UNFCCC and Kyoto Protocol programmes and financial mechanisms that are necessary to support equitable, food-secure, sustainable, and climate resilient agriculture. Shortly after the workshop was opened and talks began, however, progress was blocked, and the workshop concluded without any form of draft decision for consideration by the COP.

While this poses a significant setback, the possibility continues for the COP to adopt a work programme on agriculture if Parties re-open the discussions. The LDC Group Chair stated at the closing of SBSTA 39 at COP 19 that the "LDC Group looks forward to considering the report of the in-session SBSTA 39 workshop, along with the submissions and views the Parties expressed there. Using these views, together with the elements agreed at SBSTA 38, the LDCs hope that Parties will be able to determine a way forward at SBSTA 40." 64

\section{Eligible activities}

The range of eligible activities under REDD+ has gradually expanded from "avoided deforestation" to "REDD", or Reducing Emissions from Deforestation and forest Degradation, and finally "REDD+" which includes conservation, sustainable management of forests and enhancement of forest carbon stocks. REDD+ is currently being discussed under the UNFCCC as: 65

"Policy approaches and positive incentives on issues relating to reducing emissions from deforestation and forest degradation in developing countries; and the role of conservation, sustainable management of forests and enhancement of forest carbon stocks in developing countries."

REDD+ therefore covers all forest carbon stock changes, but excludes agriculture or other land-use emissions.

${ }^{64}$ Statement by Nepal on behalf of the Least Developed Countries Group, closing of the thirty-ninth session of the Subsidiary Body for Scientific and Technological Advice (SBSTA 39). 16th November 2013, Warsaw, Poland. http://ldcclimate.wordpress.com/2013/11/21/ldc-group-statement-at-closing-of-sbsta-39/ ${ }^{65}$ Ad-hoc Working Group for Long-term Cooperative Action (AWG-LCA), Bali Action Plan paragraph 1b(iii). 


\section{Contribution to national GHG targets}

Details on the extent to which REDD+ could contribute towards national GHG targets have yet to be agreed upon. There are a range of opinions regarding to what extent REDD+ credits could be used as an offset by developed countries. Most countries that are implementing REDD+ have not yet taken on domestic national GHG commitments.

\section{Baseline}

Baselines for REDD+ can follow a variety of approaches including historical, adjusted and projected. The negotiations on REDD+ have used the term forest reference emission levels (and alternatively forest reference level) (FREL/FRL) to demonstrate reductions in emissions from deforestation. ${ }^{66} \mathrm{FREL} / \mathrm{FRLs}$ should be developed transparently by taking into account historic data, and adjusting for national circumstances. NonAnnex I Parties can also develop subnational FRELs/FRLs as an interim measure in accordance with national circumstances. Further guidance was also provided in Warsaw on the technical assessment of FREL/FRLs, ${ }^{67}$ which will include an assessment of the data, methodologies, and procedures used.

\section{Non-permanence}

Under REDD+ permanence has been given minimal consideration at the UNFCCC level, where Parties have consented to requiring REDD+ countries to take "actions to address the risks of reversals."68

\section{Tracking Mechanism}

A tracking mechanism for REDD+ has not yet been established. Numerous attempts have been made to begin discussions on how to track emissions but these have largely been seen as premature.

\subsubsection{Ongoing accounting discussions under the UNFCCC}

CMP7 in 2011 initiated a series of work programmes under the Convention's Subsidiary Body on Technical Advice (SBSTA) related to several important issues for land-use accounting with a view to adopting deci-

\footnotetext{
${ }^{66}$ Decision 2/CP.13 paragraph 7(a).

${ }^{67}$ Decision 13/CP.19, Annex paragraph.

68 Decision 1/CP.16, Appendix I, paragraph 2.
} 
sions at CMP9 in 2013.69 The first work programme will consider "more comprehensive accounting" of LULUCF emissions and removals, including considering moving from an activity-based to a land-based approach or to adopting a more "inclusive" activity-based approach. A second work programme involves the expansion of eligible LULUCF activities under the CDM, while other programmes will seek to develop alternative means to provide temporary credits for addressing permanence under the CDM and to develop modalities and procedures for applying additionality. The outcome of these work programmes may have profound consequences for the treatment of LULUCF in Kyoto's second commitment period, as well as for its role in a post-2020 framework.

${ }^{69}$ Decision 2/CMP.7, paragraphs 5-10. 


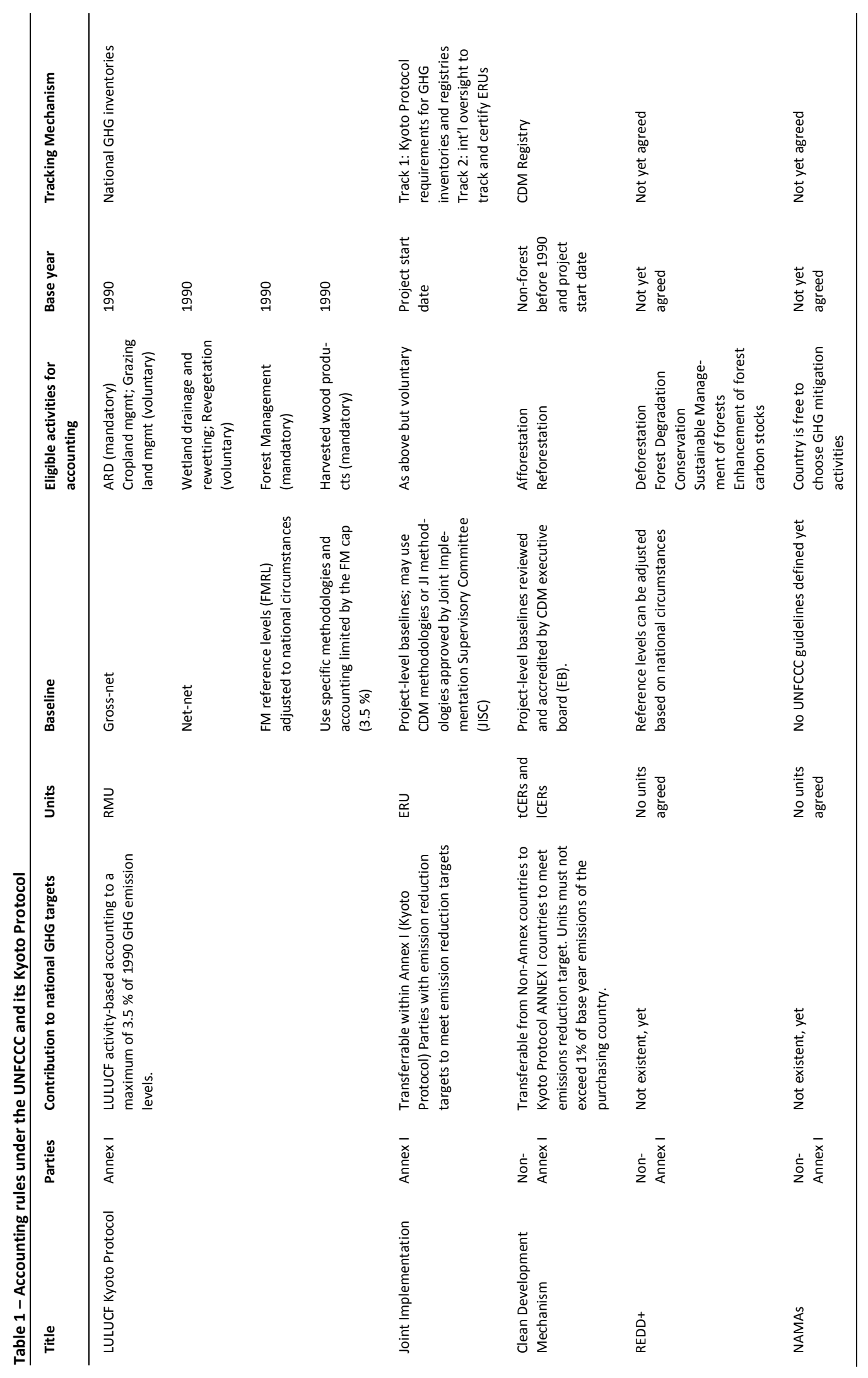




\subsection{Measurement and Reporting}

The Convention establishes a dedicated reporting framework for AFOLU that requires both developed and developing country Parties to submit national GHG inventories including both sources and sinks. ${ }^{70}$ The requirements for each grouping, however, as outlined below, are substantially different in terms of frequency and detail. In addition, the Kyoto Protocol requires Annex I Parties to develop annual inventories of their GHG emissions, which requires detailed guidelines for how these emissions should be measured and reported.

Measurement and reporting systems as outlined in Table 2 require four basic components:

- Approach: Reporting can be activity-based or land-based. Each of these approaches has advantages and disadvantages (see Box below).

- Coverage of land uses: measurement and reporting rules can be established either to require measurement and reporting on all landuses or all activities, or only some land-uses and activities.

- Uncertainty: Countries would choose the level of uncertainty to use in measurement and reporting depending on the availability of data and capacities.

- Comparability: Countries should be comparable in their national reports through consistent and common reporting.

Below, we use these four criteria to identify and assess options for measurement and reporting. The section is divided into measurement and reporting rules for Annex I Parties, the Kyoto Mechanisms (i.e. CDM and JI) and accounting rules for Non-Annex I Parties.

\subsubsection{Measurement and Reporting for Annex I Parties to the Convention}

The Convention applies a combination of land-based and activity-based reporting for Annex I Parties based on the latest good practice guidance elaborated by the IPCC (see Box 2 below). Under their NCs each country

70 UNFCCC Art. 12 
uses a land-based approach to report on all six land uses (i.e. forest lands, croplands, grasslands, wetlands, settlements and other lands). Moreover, GHG emissions from livestock, $\mathrm{N}_{2} \mathrm{O}$ emissions from managed soils, lime and urea application and harvested wood products have to be reported under the latest 2006 IPCC Guidelines for National Greenhouse Inventories. ${ }^{71}$

Annex B Parties to the Kyoto Protocol are also required to submit a detailed national GHG inventory each year that outlines national emissions and removals from the land-use sector. ${ }^{72}$ GHG inventories use an activity-based approach with mandatory reporting on emissions and removals from afforestation, reforestation, deforestation, forest management and harvested wood products (HWP) and voluntarily reporting on other land-use activities (i.e. cropland management, grazing management and revegetation). In order to ensure comparability and transparency between countries' reporting, the UNFCCC adopted reporting guidelines on annual inventories in 2006. ${ }^{73}$ Under these guidelines, each country is obliged to use the common reporting format (CRF), which is a standardized tabular format for reporting estimates of greenhouse gas emissions and removals and other relevant information. The CRF is intended to facilitate the processing of inventory information, to allow for improved handling of electronic submissions, and to support technical analysis of submissions.

Currently the use of a land-based approach for NCs and an activitybased approach for GHG inventories is unproblematic since the Convention requires only reporting on NCs and not substantive action. In comparison, GHG inventories are supposed to show the impact of direct, human-induced activities only.

\footnotetext{
71 It was finally agreed up on in Warsaw Decision -/CMP.9 Guidance for reporting information on activities under Article 3, paragraphs 3 and 4 of the Kyoto Protocol.

72 Decision 11/CP.4, paragraph 2.

73 Decision 14/CP.11.
} 


\section{Box 2 - The Intergovernmental Panel on Climate Change and its role in land use}

The Intergovernmental Panel on Climate Change (IPCC) plays a key role in developing "guidelines and guidance" for the land-use sector. The 2006 Guidelines for National GHG Inventories (hereafter IPCC Guidelines) and associated 2003 Good Practice Guidance for Land Use Land Use Change and Forestry (hereafter IPCC GPG) provide methodologies and advice for estimating GHG emissions by sources and removals by sinks. These documents have been developed through in iterative process and are referred to in numerous decisions on land use to ensure that information will be provided in a transparent, consistent, comparable, comprehensive and accurate manner.

Both the Guidelines and the GPG refer to a "tiered approach" for measurement and reporting land-use emissions that allows for differing capacities across countries. In general, moving to a higher tier improves the accuracy of reporting and reduces the uncertainty, but the complexity and resources required also increases for higher tiers. Tier 1 uses generic equations (i.e. default allometric equations) and national default values (for emissions factors) provided by the IPCC; Tier 2 uses generic equations but uses data acquired at the national level by means of a national forest inventory; and Tier 3 uses both nationally produced equations as well as national field data. If needed, a combination of tiers can be used, e.g., Tier 2 can be used for biomass and Tier 1 for soil carbon.

The IPCC Guidelines also define three "approaches" for calculating land-use change. Approach 1 is the simplest of approaches and only measures and reports net changes in a land-use area; the exact location or pattern of land-use change and the exact changes in land-use categories are not calculated. Approach 2 improves upon approach 1 by providing an assessment of both the net losses and gains in specific land-use categories as well as what these conversions represent (i.e., changes both from and to a category). The final result of this Approach can be presented as a non-spatially-explicit land-use conversion matrix. Approach 3 is the most complex and uses spatially explicit observations of land-use categories and land-use conversions, often tracking patterns at specific point locations and/or using gridded map products, such as those derived from remote sensing imagery.

Finally, IPCC guidance defines two types of carbon accounting: land-based and activity-based accounting. Under land-based accounting the total carbon stock change in applicable carbon pools on particular land units are reported (e.g. a Party's territory). Land-based accounting, in theory, uses a "wall-to-wall" comprehensive inventory of all carbon over the chosen land units. This approach is demanding when it comes to data, analysis and expense, but has the clear advantage that it includes all land-use activities and avoids double counting. Land-based accounting, 
however, may inadvertently include emissions that are not the product of human activity (e.g. emissions arising from natural disturbances). ${ }^{74}$

An activity-based approach begins with the carbon stock change attributable to designated activities. First, each applicable activity's impact on carbon stocks is determined per unit area, which is then multiplied by the area on which each activity occurs. Aggregate emissions or removals are calculated by summing across applicable activities. To avoid a given area of land being counted more than once if it is subject to multiple activities, each land unit should contain no more than one activity.

Recent developments under the Convention have seen some additional changes emerging with respect to emissions reporting. COP 17 in 2011 adopted modalities and procedures for biennial reports (BRs) submitted by developed country Parties. 75 These BRs include not only inventories but also progress towards achieving Parties' emission reduction targets and mitigation actions for the year 2020 pledged under the Copenhagen Accord, ${ }^{76}$ which in many cases include land-based emissions. ${ }^{77}$ While it is not clear which reporting rules should apply to these commitments, recent practice suggests that developed country Parties - both those participating and not participating in the second commitment period of the Kyoto Protocol - continue to use the Kyoto Protocol's LULUCF reporting framework for their BRs.

\subsubsection{Measurement and Reporting under the Kyoto Mechanisms}

Under the CDM and JI, measurement and reporting follows projectbased carbon baseline and monitoring methodologies. Each Party must report annually in a standard electronic format (SEF) information on allowances and credits from its national registry for the previous calendar year. Baseline and monitoring methodologies outline a step-wise approach to measurement and reporting of GHG emissions and emissions reductions from specific project-based activities. Project owners use a standardized project design document (PDD) template as the basis

\footnotetext{
74 Ibid.

75 Decision 2/CP.17, Annex II.

76 Decision 2/CP.15.

77 Decision 2/CP.17, paragraphs 23-36 and Annex II.
} 
for measurement and reporting. The methodologies for JI and CDM generally pose significantly higher data quality and uncertainty requirements and normally follow a Tier 2 or Tier 3 approach. Project developers have to report on the performance of the project activity using fieldbased measurements at a minimum every 5 years, based on measurements collected in the intervening period.

\subsubsection{Measurement and Reporting for Non-Annex I Parties to the Convention}

Developing country Parties have until recently only been required to prepare national GHG inventories as part of NCs submitted every four years that are subject to less stringent guidelines than developed country Parties. ${ }^{78}$ Recent decisions, however, now require Non-Annex I Parties to submit biennial update reports (BURs) every two years outlining among others things mitigation actions undertaken since their last NC and their GHG inventories. Measurement and reporting for BURs and NCs for developing country Parties follows the same IPCC guidance as applies to Annex I Parties. Countries thus identify key categories based on the latest IPCC good practice guidance and report on all six land-uses, GHG emissions from livestock, $\mathrm{N}_{2} \mathrm{O}$ emissions from managed soils, lime and urea application and harvested wood products.

At COP 19 in Warsaw in 2013, countries reached agreement that measurement and reporting for REDD+ should use national forest monitoring systems that are based on the most recent IPCC guidance and guidelines and that MRV for REDD+ should be aligned with MRV for NAMAs, which is subject to further development. ${ }^{79}$ Countries are currently free to choose whether to adopt a land-based or an activity-based approach, though data and information should be "transparent and consistent over time and with the established forest reference emissions levels." 80

While the decisions and guidance for NAMAs does not include any guidance on coverage, uncertainty levels and comparability, the REDD+ decision indicates the requirement to measure and report "anthropogenic forest-related greenhouse gas emissions by sources, and removals by sinks, forest carbon stocks, and forest carbon stock and forest-area chang-

\footnotetext{
${ }_{78}$ Decision 10/CP.2 and Decision 17/CP.8.

${ }^{79}$ Decision 11/CP.19.

80 Decision 13/CP.19.
} 
es." 81 This implies that countries seeking to access results-based finance would be required to report on afforestation, reforestation, deforestation and forest management, if relevant in the country context.

\subsubsection{Ongoing Measurement and Reporting discussions under the UNFCCC}

In 2011 Annex I Parties were invited to make submissions of views by 1 March 2014 on their experience with reporting their first Biennial Reports. ${ }^{82}$ The current SBSTA work programme on comprehensive landuse accounting post 2020 initiated in 2011 is mainly focused on accounting issues, but includes also work on the alignment of measurement and reporting systems for developed and developing countries.

81 Decision 11/CP.19.

82 Decision 2/CP17. 


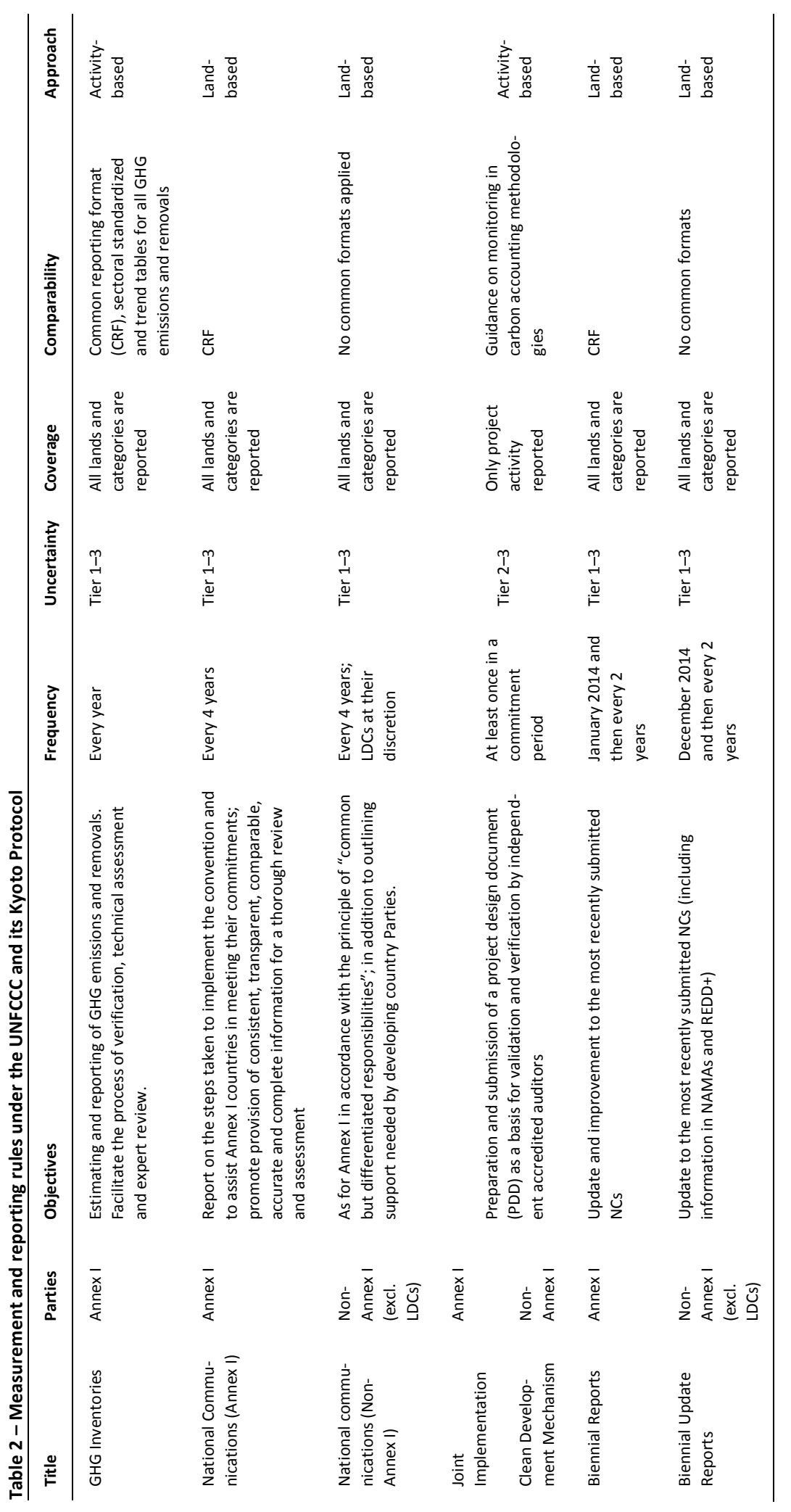




\subsection{Verification}

Since 2011, verification has been split into two processes. ${ }^{83}$ Annex I Parties are subject to International Assessment and Review (IAR) of their actions related to "Nationally Appropriate Mitigation Commitments" and reporting through NIR, BR and NCs. Non-Annex I Parties must undergo a process of International Consultation and Assessment (ICA) on their mitigation achievements and support received that is "non-intrusive, non-punitive and respectful of national sovereignty." The SBSTA work programme on the "revision of the guidelines for the review of biennial reports, national communications, including national inventory reviews, for developed country Parties" was completed in Warsaw in 2013. The work programme focused on the improvement of cost-effectiveness, transparency and better coordination between the three review processes for NCs, inventories and BRs.

In addition to the national level verification processes, the UNFCCC has adopted independent third party verification processes for the CDM and JI. The CDM and JI verification processes assess whether the implementation and the operation of a project activity and steps taken to measure and report emissions reductions have actually occurred. The remainder of this section outlines verification rules for Annex I Parties, under the Kyoto Mechanisms (i.e. CDM and JI) and for Non-Annex I Parties.

\subsubsection{Verification for Annex I Parties to the Convention}

Since 2003, annual GHG inventories have become mandatory for all Annex I countries. These inventories are subject to an annual review. The National Inventory Review (NIR) contains three major stages, each of which result in a report. 84

Initial check: A brief quality assurance check is undertaken to assess that the report submitted is complete and in the correct format. This process is mainly based on the CRF submission. A resulting status report is produced.

\footnotetext{
${ }^{83}$ Decision1/CP.16.

${ }^{84}$ Decisions 2/CP.1 and 6/CP.3.
} 
Synthesis and assessment: The first part of this process compiles and assesses basic inventory information, such as emission trends, activity data and implied emission factors, across Parties and over time. In the second part of this process a preliminary assessment of the inventory of individual countries is undertaken.

Individual review: Inventory experts from the expert review teams (ERTs) examine data, methodologies and procedures used in preparing the national inventory. This is the most detailed review stage. An ERT undertakes 5-8 inventory reviews. The review is based on desk reviews. Reviewed Parties receive technical feedback from other experts, which enables them to further improve their inventories.

ERTs are comprised of two lead reviewers, one each from an Annex I and a non-Annex I Party to guide the work of the teams. The Secretariat also selects experts to ensure coverage of all inventory sectors to achieve an overall balance in the participation of experts from Annex and non-Annex I Parties.

Since 2011 developed countries have been further subject to an International Assessment and Review (IAR) of BRs in order to promote comparability among developed countries with regard to their quantified economy-wide emission limitation and reduction targets. ${ }^{85}$ IARs include a technical "in-depth review" by the ERT and produce an individual review report for each country before submitting it to the Compliance Committee. The review includes a desk-based study and an incountry visit, and aims to provide a comprehensive, technical assessment of a Party's implementation of its commitments under the Convention. In addition, upon request from the Subsidiary Body of Implementation (SBI), the Secretariat prepares compilation and synthesis reports of the NCs that summarize information provided in the individual NCs.

Under IAR, coordinated by the Subsidiary Body for Implementation (SBI), the ERT is composed of experts listed in the UNFCCC roster of experts, which includes an AFOLU expert. The Compliance Committee is made up of two branches: a facilitative branch and an enforcement branch. The facilitative branch provides advice and assistance to countries in order to promote compliance. The enforcement branch is responsible for determining consequences for countries not meeting their commitments. Both branches are composed of 10 members, including one representative from each of the five official UN regions, one from the

85 Decision 19/CP.8. 
Small Island Developing States, and two each from Annex I and nonAnnex I Parties.

\subsubsection{Verification under the Kyoto Mechanisms}

The CDM validation/verification process is based on a desk-review and onsite assessment examining whether project documentation and monitoring is in accordance with the requirements of the registered project design document and relevant provisions of Decision 17/CP.7. Verification also includes a review of monitoring results and verifies compliance with the monitoring methodology, recommending appropriate changes, if relevant, and confirming the achieved GHG emissions reductions. The DOE produces a verification report that is made publicly available on the UNFCC website. Moreover, the DOE is required to produce a certification statement, confirming the verified emissions reductions have been achieved.

Similar to the DOEs, under JI track 2 verification, the AIE undertakes an assessment of the PDD, the monitoring report, data collected, and other evidence supporting the emission reductions, and produces a verification opinion and a statement confirming that the emissions reductions are accurate and free of material errors, omissions, or misstatements. Based on that, the JISC appraises the verification report submitted by the AIE and determines whether the criteria for verification were met. Under Track 1, verification may also be carried out by AIEs, with more detailed rules or national requirements.

The frequency of verification is flexible, but should take place at least once in each commitment period in order to be able to transfer CERs or ERUs.

\subsubsection{Verification for Non-Annex I Parties to the Convention}

At COP 16 in Cancun, a new verification mechanism to analyze BURs was adopted for Non-Annex I Parties. International Consultation and Analysis (ICA) aims to "increase transparency of mitigation actions and their effects," 86 through analysis by technical experts in consultation with the Party. The process will be conducted in a manner that is "non-intrusive,

${ }^{86}$ Decision 1/CP.16 paragraph 63. 
non-punitive and respectful of national sovereignty" and will not go into the "appropriateness of domestic policies and measures." 87

The first round of ICA will be undertaken within six months of the submission of the BURs by developing countries. From then on ICA will be conducted in time with BUR submissions, which is currently biennial, while special flexibility will be given for Small Island Developing States and Least Developed Countries. A revision of modalities and guidelines for ICA will be undertaken after the first round of ICAs, and no later than 2017.

The ICA will draw on the same pool of experts as the IAR process (i.e. Expert Review Teams). The team of technical experts in consultation with the Party reviews the information provided and produces a draft summary report. The draft summary report is shared with the country of assessment over a three-month period and should incorporate country comments. The reports will then be finalized in consultation with the country and presented to the SBI, to be made publicly available on the UNFCCC website.

In the context of REDD+, ICA will be conducted by at least two LULUCF experts from the UNFCCC roster of experts when reviewing national measurement and reporting systems, national forest monitoring systems and references levels. ${ }^{88}$ For REDD+ countries seeking resultbased payments, verification will be also based on ICA and in accordance with NAMA verification. If market-based approaches are developed for REDD+, further specific modalities for verification may be developed that could be negotiated through discussions on "New Market Mechanisms" or under a common "Framework of Various Approaches."

\subsubsection{Ongoing Verification Discussions under the UNFCCC}

The objectives of both verification streams such as ICA and IAR were agreed upon at COP 17. Over the past two years the SBSTA "work programme on the revision of the guidelines for the review of biennial reports, national communications, including national inventory reviews, for developed country Parties" was accomplished in Warsaw in 2013. The work programme focused on the improvement of cost-effectiveness, transparency and better coordination between the three review pro-

${ }^{87}$ Decision 2/CP.17, Annex IV.

${ }^{88}$ Decision 19/CP.19. 
cesses for NC, inventories and BRs. Parties agreed on guidelines for reviews of NCs and BRs.

For ICA at COP 17 (Durban, 2011) it was also agreed that a review of procedures and modalities should take place after the first round of submissions and reviews no later than in 2017. For IAR, Parties agreed that modalities and procedures will be revised no later than 2016 (COP 22), after reviewing experience from the first round reviews. Thus there are currently no ongoing political negotiations on the objectives of both verification streams under the UNFCCC. 


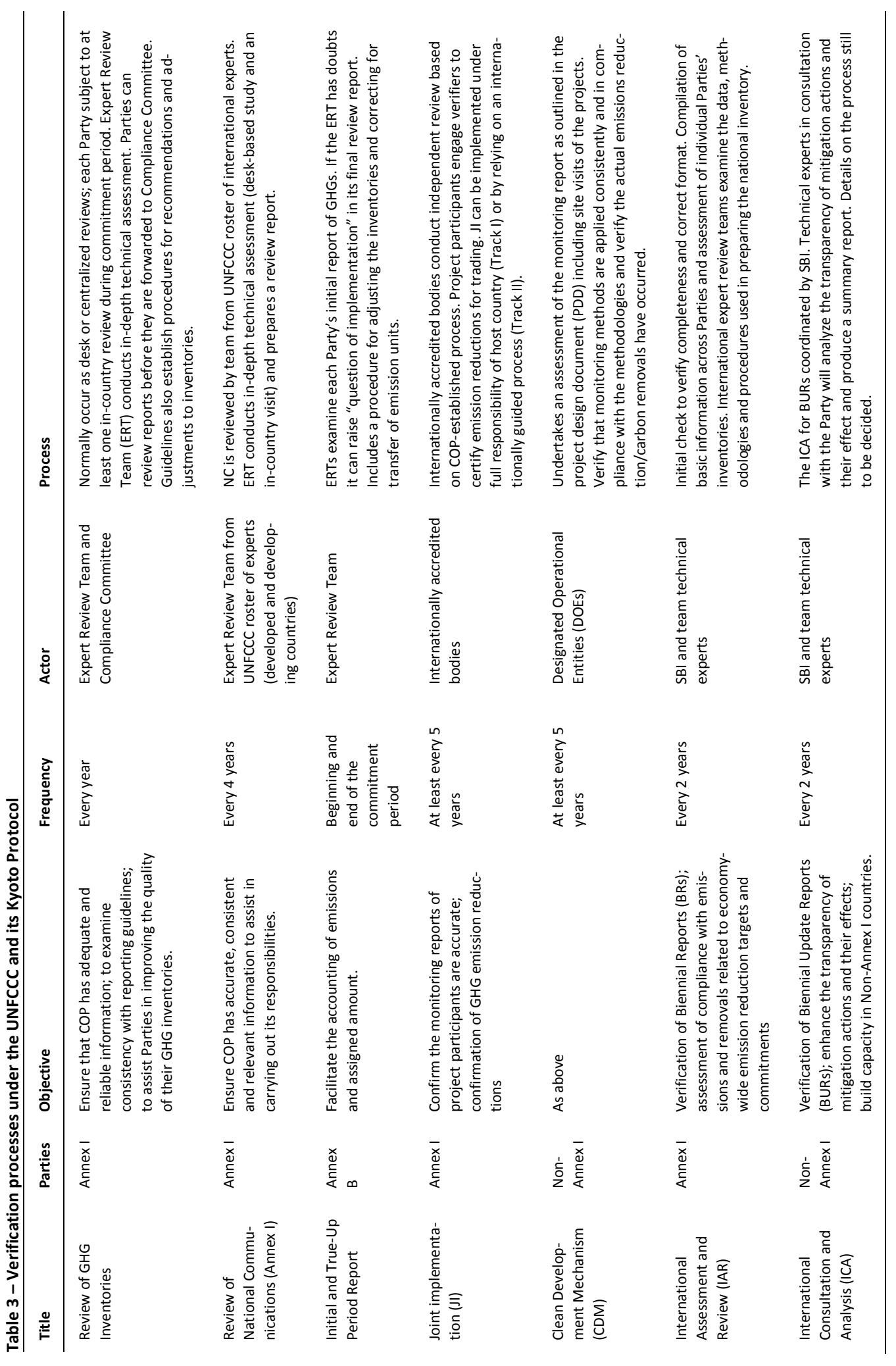




\section{Options Analysis: Convergence and Synergies}

\subsection{Overview}

The current framework for land-use accounting is highly fragmented, complex and fails to create incentives for ambitious climate change mitigation from the land-use sector. This section considers options for consolidating the various mechanisms in the context of a future climate treaty, taking into account the current lines of convergence and divergence across the major faultlines of the Convention; i.e. the divisions between climate change mitigation and adaptation, agriculture and forestry, and developed and developing countries

\subsection{Four overarching options}

Under a post-2020 framework Parties are expected to take on varying contributions to climate change mitigation. These contributions can be expressed in absolute or relative mitigation commitments, or can relate to certain activities. The various approaches can be categorized as follows (see Figure 1):

- National economy-wide targets: Countries with higher contributions to GHG emissions (e.g. current Annex B countries, and other OECD countries) will be expected to take on economy wide targets to reduce GHG emissions. How such targets will include land-use emissions is not yet clear and will depend on the overall architecture of a post-2020 agreement.

- National or subnational sectoral baselines: Countries that elect not to take on economy-wide targets may choose to communicate mitigation goals against national or subnational sectoral baselines and implement sectoral GHG mitigation activities such as those under the framework of REDD+ or NAMAs. 
- Project-level sectoral baselines: Countries may also choose to engage in project-level sectoral approaches. Currently, these project-based mechanisms are limited in scope and follow different rules for developed (JI) and developing (CDM) countries. A project-level sectoral approach would expand upon and harmonize current project level methodologies.

- Policies and measures: Finally, countries that either elect not to, or do not have the ability to announce mitigation goals could commit to adopt policies and measures to reduce land-use emissions.

The degree of comparability and consistency between these systems including the fungibility of allowances and potential credits issued under the various approaches would be a matter of negotiation. In all cases, where credits are issued and used towards mitigation targets of other countries, rules that determine eligibility are likely to apply. All approaches would have to consider issues of non-permanence and subnational systems would also have to provide strategies to address leakage.

\section{Figure 1 - Four overarching options for a post-2020 land-use framework}

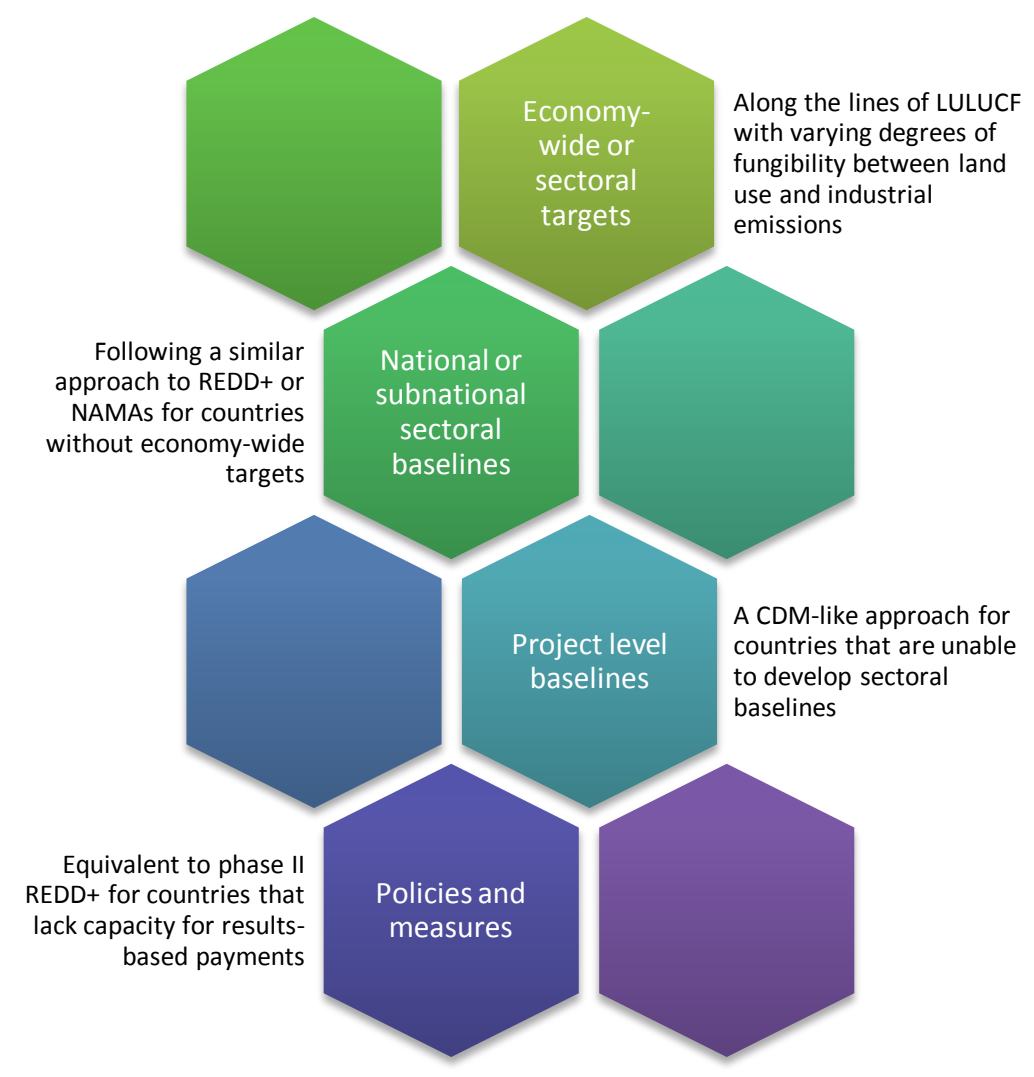


Using these four overarching options, the following sections identify how the individual components of measurement and reporting, verification, and accounting would align with these options and what the implications would be for a post-2020 land-use agreement.

\subsection{Accounting of land-use in post-2020 framework}

Accounting rules as defined in Table 1 need to fulfill the following basic criteria:

- Contribution to national GHG targets: To what extent do emissions reductions or removals from the land-use sector contribute to national targets?

- Baseline: How are emissions reductions generated, i.e. below a base year, or using a reference level? Are emissions accounted for using gross-net or net-net accounting?

- Eligible activities for accounting: Is accounting land-based or activitybased? If activity-based accounting is used, which activities are voluntary and which are mandatory?

- Non-permanence: How is non-permanence addressed and what units will be generated from land-use activities (such as tCERs and RMUs). Is there fungibility (i.e. emissions are exchangeable and tradable) between emissions reductions from land-use and other sectors?

- Tracking Mechanism: How are credits or allowances recorded and tracked? This is relevant both for domestically generated as well as internationally traded emissions reductions and removals.

Using these five criteria the following section elaborates how the various overarching options could be established under a post-2020 framework.

\subsubsection{Contribution of accounting rules to national GHG targets}

During the development of the Kyoto Protocol controversies about GHG mitigation and data insecurities led to a set of accounting rules for land use that are both complex and fail to provide full incentives to countries to make significant mitigation contributions through the land-use sector. In addition, there were concerns that emissions from land use would undermine overall mitigation ambition. The following subsections out- 
line how the contributions to national GHG targets could be dealt with within the four overarching options outlined above.

\section{National economy-wide targets}

A variety of approaches could be adopted for countries with national economy-wide targets to allow countries to achieve higher levels of mitigation from the land-use sector:

- Single target: Under this approach land use would fall under a single national target. Considering the often lower marginal abatement costs of the land-use sector, this approach would provide the largest incentive for countries to reduce emissions from the land-use sector. Considering the variations and uncertainties in land-use accounting, the targets would have to be set carefully and backed by robust MRV rules.

- Dual targets: Countries could specify separate targets for the landuse and non-land-use sectors. Emissions reductions would be completely unfungible (i.e. not exchangeable nor tradable) between sectors. This would allow countries to set ambitious mitigation targets in the land-use sector without undermining other sectoral ambition. Tradability between countries would be possible depending on the level of stringency of MRV systems in host countries as well as the potential flow of emissions reductions from these countries.

- Capped: A hybrid approach would introduce caps that limit the amount of emissions reductions (or removals) that can be achieved from the land-use sector. To avoid the complexities that arose during the Kyoto Protocol, these caps should be simple, transparent and comparable across countries.

\section{National or subnational sectoral baselines}

National sectoral baselines could exist in parallel with - or as an alternative to - national economy-wide targets. Baseline-and-credit systems when used in conjunction with national targets could cover land-use activities burdened by particular uncertainty levels in measurement and reporting. ${ }^{89}$ Credits generated by countries with national sectoral baselines could also be used to offset emissions under target-based systems.

\footnotetext{
${ }^{89}$ An example of a link between a baseline-and-credit system with a target-based system is the accounting for forests management in the second commitment period of the Kyoto Protocol.
} 
The simplest approach would be to allow countries to meet any percentage of their economy-wide target through land-use credits. Accounting rules would need to be established that ensure that credits were backed by robust MRV rules. As an alternative, countries could introduce caps that limit the amount of emissions reductions (or removals) that can be achieved from the land-use sector.

\section{Project-level baselines}

Credits can also be generated under project-level baselines. Current Kyoto Protocol rules limit the extent to which RMUs, tCERs and ICERs can contribute towards national targets (in countries that have them). ${ }^{90}$ Future accounting rules could follow several approaches:

- Unlimited: Under this scenario, offset credits would not be capped in countries with economy-wide targets. This would arguably raise the level of ambition in these countries but would reduce the incentive for emission reductions in industry or energy sectors.

- Capped: Post-2020 accounting rules could follow a similar approach to current Kyoto Protocol rules. Caps could be set at the current level of $1 \%$ of base year emissions or could be renegotiated.

- Unlimited under dual target: A final alternative is to allow unlimited credits in countries that have dual targets. This would potentially allay concerns regarding permanence as well as substituting industrial emissions reductions with land-use reductions.

\subsubsection{Baselines}

Under current UNFCCC accounting rules, benchmarks have been established very differently for Annex I and Non-Annex I Parties. Annex I Parties use a combination of base years and reference levels across different activities (see Section2.3.1 above). In addition, base years can use either net emissions or gross emissions as a benchmark. Non-Annex I Parties, on the other hand, use reference levels for REDD+ as a benchmark for measuring emissions reductions. These should be based on historical emissions but can be adjusted for national circumstances. A post-2020 framework should aim for consistency, both across Parties as well as within a Party's national system. Using a combination of gross-net, net-

\footnotetext{
${ }^{90}$ It is difficult, however, to say to what extent this would have played a role given the exclusion of these credits from the EU-ETS.
} 
net and reference levels has led to a complicated system of accounting for Annex I Parties in which it is difficult to assess comparability and consistency of GHG inventories.

\section{National economy-wide targets or sectoral baselines}

Both countries with economy-wide targets and countries that adopt national sectoral baselines could establish baselines using any of the following three basic approaches: ${ }^{91}$

- A base year against which to measure emissions reductions is the simplest form of accounting benchmark. Where possible, base years should be transparent, comparable between countries and consistent across activities. A baseline that uses net emissions in the base year is mathematically similar to an historical reference level, and would therefore potentially allow a degree of comparability between countries with historical reference levels. ${ }^{92} \mathrm{~A}$ baseline that uses gross emissions in the base year, on the other hand, would not account for removals in that year and would therefore offer less comparability with other benchmarks.

- Reference levels can be established using a range of methodological approaches including purely historical, adjusted, and projected.9394 The development of these reference levels should aim to ensure environmental integrity and comparability across countries. Projected and (upwardly) adjusted reference levels, would need to be considered carefully, in particular if they produce offsets.

- Emissions intensity baselines would be more complex as they would generate emissions reductions against another variable e.g. Gross Domestic Product (GDP). National emissions reductions could still be calculated ex-post by factoring out the effect due to changes in GDP. Uncertainty in the underlying variable, would result in further uncertainty in emissions intensity during the accounting period.

\footnotetext{
${ }^{91}$ Adapted from Morgan, J. et al. (2013). A Pathway to a Climate Change Agreement in 2015: Options for Setting and Reviewing GHG Emission Reduction Offers, WRI.

92 With the exception that a base year target only accounts for emissions for a single year and not over an historical average.

93 Parker, C., et al. (2009). The Little REDD+ Book. Oxford, GCP.

94 Meridian Institute (2011). Modalities for REDD+ Reference Levels: Technical and Procedural Issues. Prepared for the Government of Norway, by Arild Angelsen, Doug Boucher, Sandra Brown, Valérie Merckx Charlotte Streck, and Daniel Zarin.
} 
As described above, the choice of baseline would impact the degree of fungibility between accounting systems. Standardization of baselines as well as guidance on the review of baselines would increase the degree of fungibility between countries.

\section{Project-level baselines}

Project-level baselines have to-date followed two basic approaches. Under the flexible mechanisms, projects have typically used historical reference levels that may be adjusted for suppressed demand or other national circumstances. Baselines under JI are defined as:

"the scenario that reasonably represents the anthropogenic emissions by sources or anthropogenic removals by sinks of greenhouse gases that would occur in the absence of the proposed project." 95

Baselines must be justified, take into account relevant national and/or sectoral policies and circumstances, and should also take into account uncertainties and use conservative assumptions. ${ }^{96}$ Methodologies approved by the Executive Board of the CDM may be applied to JI projects.

\subsubsection{Eligible activities for accounting}

To ensure that all accounted emissions and removals are direct and human-induced, current LULUCF accounting rules use an activity-based approach. Under a post-2020 framework, land-use accounting could use an activity-based approach, a land-based approach or a combination of both. Under both approaches, accounting rules can be established to require measurement and reporting on all activities, or only on some landuses and activities. Full coverage is desirable to ensure consistency and comparability between Parties' reports, as well as minimizing leakage into land-use types caused by implementation of the mitigation actions that are not accounted for. Parties' capacities to implement full land-based or activity-based accounting, however, will differ. To address this issue, a post-2020 framework could adopt flexible guidelines for reporting against activities, and allow a country to opt-in to accounting for particular activities once data availability and capacities are in place. Under this approach more developed countries would be required to report against a fuller

\footnotetext{
${ }^{95}$ Appendix B to Decision 9/CMP.1.

${ }^{96} \mathrm{http}$ ///theredddesk.org/markets-standards/joint-implementation-ji-kyoto-protocol
} 
range of activities and less developed countries could choose activities voluntarily. If an opt-in approach is used, and countries are free to select individual activities, comparability would be difficult to achieve. In addition, if emission trading is desired then minimum thresholds for eligible activities may be required to prevent leakage.

\subsubsection{Non-permanence}

There are various strategies to account for the reversal risk inherent in LULUCF activities. Most of these strategies have been developed for offset and baseline-credit systems, although they would arguably be relevant for emission trading under any system.

The issue of non-permanence under current accounting rules has resulted in the establishment of tCERs and ICERs for developing countries under the CDM, whereas permanence for Annex I countries was not considered, and both LULUCF and JI accounting rules consider RMUs (and ERUs) to be permanent within a commitment period. This asymmetrical divide is something to be considered in a post-2020 framework. Various options have been put forward under recent negotiations to replace the current system of tCERs and lCERs that would result in more fungibility of emissions reductions: ${ }^{9798}$

- Buffers have been proposed as a means to deal with non-permanence by setting aside a portion of emissions reductions instead of selling them. If a natural hazard or human act, i.e. a reversal occurs, then emissions reductions within the buffer can be used to compensate for this loss.

- Discounting is similar to buffering: only a portion of generated emissions reductions are actually used to allow for risk of reversal, e.g. if a buyer purchases 100 credits, only 80 will be accounted for. Emissions reductions are not held in a buffer in this case; they are simply retired or remain unaccounted.

- Country guarantees have been proposed as an additional measure that host countries can take to address the risk of non-permanence.

Guarantees can be provided by a host country, buyer country, or an

\footnotetext{
${ }^{97} \mathrm{http} / / /$ unfccc.int/resource/docs/2013/sbsta/eng/misc18.pdf

${ }^{98} \mathrm{http}$ //unfccc.int/resource/docs/2013/sbsta/eng/misc18a01.pdf
} 
authorized third party. Guarantees can be combined with other approaches e.g. buffer, insurance.

- Insurance premiums can be paid to an insuring entity that guarantees against reversal risk by replacing credits affected by reversal. This approach transfers risk to a third party, which may be desirable in cases where the host country is not able to provide risk mitigation.

\subsubsection{Registries}

If emissions reductions are transferred between countries, additional annual reporting on the units transferred is required using a "standard electronic format" as used by the Kyoto Protocol Parties to report on their units' utilization and transfer. In order to enhance transparency and avoid double counting, a national registry would be required that would link the national emissions reduction activities, with the UNFCCC tracking platform and if used internationally, it would be linked with registries of other countries. 


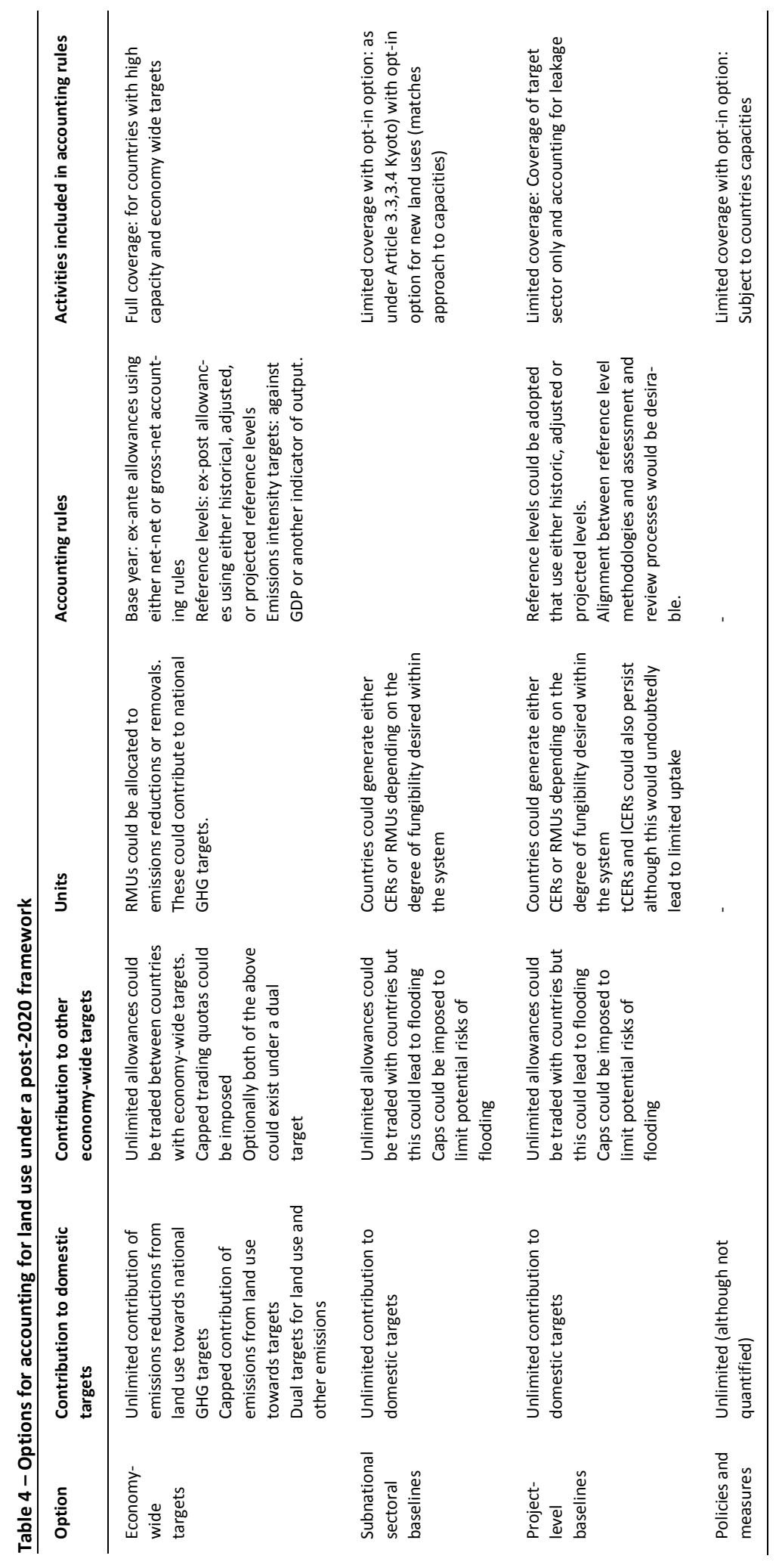




\subsection{Measurement and reporting of land use in post- 2020 framework}

Under the current accounting framework, measurement and reporting requirements differ for Annex I and Non-Annex I Parties. Annex I Parties are required to provide annual GHG inventories across the entire land-use sector whereas Non-Annex I Parties are required only to report every 4 years through their national communications. BURs and BRs have drawn these groups closer together but the level of detail required in BRs is still far greater. There are also specific requirements for measurement and reporting for countries that participate in specific mitigation mechanisms, such as the CDM. Emerging mechanisms, such as new market mechanisms, and mechanisms related to REDD+ and NAMAs can also be expected to have specific measurement and reporting requirements, the details of which will differ depending on how the mechanism operates.

In general, measurement and reporting systems that underpin the transfer of emission reductions from one Party to another can be expected to have more stringent requirements. A further issue concerns capacities. Under a post-2020 arrangement, the measurement and reporting framework will need to consider differences in countries' capacities and provide sufficient flexibility and incentives to improve data quality and provide GHG emissions reductions from the land-use sector.

It is generally accepted that measurement and reporting practices should adhere to the basic principles for national GHG inventories as outlined by the IPCC, i.e. they should be transparent, consistent, comparable, complete and accurate. Measurement and reporting systems can be broken down into three basic components as outlined in Section 2.4 over:

- Approach: Reporting can be activity-based or land-based. Each of these approaches has advantages and disadvantages (see Box 2 above).

- Uncertainty: Countries would choose the level of uncertainty to use in measurement and reporting depending on the availability of data and capacities.

- Comparability through reporting

Below, we use these three criteria to identify and assess options for measurement and reporting. 


\subsubsection{Measurement approach (land-based or activity based):}

Under a post-2020 framework, countries can choose to adopt either a land-based approach, an activity-based approach or some combination of the two.

A land-based approach would in general require less capacity than an activity-based approach, since all Parties currently use this approach for measurement and reporting under NCs. Common tabular format (CTF) reports could be used to ensure comparability and completeness. If land-based accounting were used however, care would need to be taken to ensure that non-human-induced changes in land-use or land-cover could be distinguished from anthropogenic emissions and removals.

Alternatively, an activity-based approach could build on the current Kyoto Protocol LULUCF framework as a parallel measurement and reporting framework to the land-based reporting in the national inventories. Data needs for full land-use sector accounting would be very demanding and would exclude many countries from participation. NonAnnex I Parties, who are currently not subject to the Kyoto Protocol LULUCF accounting framework, would need to develop their capacity to report emissions and removals on individual activities.

Ultimately, a post-2020 framework could elect to use a combined approach, in which individual Parties choose to use either a land-based or an activity-based approach for measurement and reporting. Under this scenario, it would be difficult to see how comparability across countries would be achieved.

Using either approach, if mitigation actions are to result in tradable emission reductions, it would be expected that Parties should follow a higher tier methodology in measurement and reporting. For projectlevel approaches this could follow the precedent set by current methodologies used in the CDM or JI, and adopt an activity-based approach with a high resolution of monitoring data. At the national level, Parties could simply use their national GHG inventories as the basis for international emissions trading.

Countries that take on national policies and measures would not generate tradable emission reduction units but would only measure and report in the framework of their NCs and BURs. Because activity-based approaches are more data-intensive, countries in this category would most likely use the land-based approach as practiced by all Parties following IPCC 2006 Guidelines. 


\subsubsection{Uncertainty}

IPCC 2006 Guidelines provide for three levels of GHG measurement and reporting, i.e. tier 1 , tier 2 or tier 3 measurement approaches. The Tier 1 approach uses default values provided by the IPCC, while at the other extreme the Tier 3 approach uses methods that reflect site-specific conditions in the country. Tier 3 approaches should be associated with less uncertainty than Tier 1 or Tier 2 approaches. Countries should choose a level of uncertainty that matches their national capacity and availability of data.

Where the purpose of measurement and reporting is to achieve a high degree of comparability between reports (i.e. for countries with economy-wide targets), or to transfer emission reductions between sectors or between Parties, there should be more stringent requirements of precision and accuracy leading to low uncertainty levels in order to ensure comparability between units of emission reduction. This would require that at least Tier 2 or Tier 3 approaches are adopted.

If full accounting is not required, high uncertainty levels would be acceptable. Parties would be encouraged to increase the coverage of subsectors and improve upon levels of uncertainty in order to have access to additional incentives for fully fungible emissions reductions or removals.

\subsubsection{Comparability}

Consistency and comparability can be supported through the use of standardized reporting formats, e.g. CTF tables that are used by all Annex I Parties. These could be supplied alongside national GHG inventories, BRs, BURs and NCs. If emission reductions from national sectoral mitigation actions are to be used internationally, comparability requirements would be stronger. If emissions reductions are not used internationally, there would be less demand for comparable reporting formats, because no internationally transferrable units are exchanged. 
Table 5 - Options for measurement and reporting of land use post-2020

\begin{tabular}{|c|c|c|c|}
\hline Option & Measurement Approach & Uncertainty & Comparability \\
\hline $\begin{array}{l}\text { Economy- } \\
\text { wide } \\
\text { targets }\end{array}$ & $\begin{array}{l}\text { Land-based approach: consistent with } \\
\text { existing reporting under the Convention } \\
\text { through NCs; comparable between } \\
\text { countries; less incentive for mitigation } \\
\text { actions. } \\
\text { Activity-based approach: based on } \\
\text { Kyoto Protocol reporting. Reflects } \\
\text { activities, so better aligned with incen- } \\
\text { tives; can be very data demanding and if } \\
\text { not complete can lead to limited compa- } \\
\text { rability and "cherry picking" } \\
\text { Combined approach: matches approach } \\
\text { with capacities; comparability weaker. }\end{array}$ & $\begin{array}{l}\text { Low uncertainty levels (Tier } 2 \\
\text { and 3): For sub-sectors subject to } \\
\text { accounting and generation } \\
\text { transferrable units. } \\
\text { High uncertainty levels (Tier } 1 \\
\text { and 2): For sub-sectors not } \\
\text { accounted for, but with incen- } \\
\text { tives to improve capacity for } \\
\text { accounting and coverage. }\end{array}$ & $\begin{array}{l}\text { Common reporting: Consistency and } \\
\text { comparability through standard } \\
\text { formats (e.g. CRF) for Inventory } \\
\text { Reporting, NC and BURs/BRs, in case } \\
\text { of accounting. } \\
\text { Flexibility of reporting: If no account- } \\
\text { ing (transferrable units), countries } \\
\text { may select reporting formats as no } \\
\text { comparability required. }\end{array}$ \\
\hline $\begin{array}{l}\text { Project- } \\
\text { level } \\
\text { baselines }\end{array}$ & $\begin{array}{l}\text { Activity-based approach: For market- } \\
\text { based mechanisms, existing or new } \\
\text { activity-based carbon accounting } \\
\text { methodologies based on } 2006 \text { IPCC } \\
\text { Guidelines. }\end{array}$ & $\begin{array}{l}\text { Low uncertainty levels (Tier } 2 \\
\text { and 3): For mitigation actions } \\
\text { subject to accounting and } \\
\text { generation of transferrable units. }\end{array}$ & $\begin{array}{l}\text { Common reporting: For project-level } \\
\text { activities that generate transferrable } \\
\text { units common reporting formats will } \\
\text { ensure consistency and comparability } \\
\text { between countries. }\end{array}$ \\
\hline $\begin{array}{l}\text { Policies } \\
\text { and } \\
\text { measures }\end{array}$ & $\begin{array}{l}\text { Land-based approach: No change to the } \\
\text { current system: based on reporting in } \\
\text { biennial reports, biennial update reports } \\
\text { and National Communications. Differen- } \\
\text { ces in inventory systems between } \\
\text { developed and developing countries. }\end{array}$ & $\begin{array}{l}\text { High uncertainty levels (Tier } 1 \\
\text { and 2): No accounting and access } \\
\text { to sub-national instruments } \\
\text { increase incentives to improve } \\
\text { and build capacity over time. }\end{array}$ & $\begin{array}{l}\text { Flexibility of reporting: No accounting } \\
\text { (transferrable units). Reporting in NCs, } \\
\text { BURs and national inventories; little } \\
\text { requirement for comparability or } \\
\text { standardized reporting. }\end{array}$ \\
\hline
\end{tabular}

\subsection{Verification of land use in post-2020 framework}

Verification approaches would vary according to (a) whether a country has a binding emission reduction commitment, a voluntary commitment or no commitment, and (b) whether reports of emission reductions result in internationally transferable units, results-based payments or no international support or transfer of units.

\section{Economy-wide targets}

Countries with economy-wide targets will more than likely be subject to verification of annual national GHG inventories that would be undertaken by an ERT. NCs would be subject to international review by a team of experts including AFOLU experts every four years. Biennial Reporting (BR) would be subject to IAR. Countries that shifted from a sectoral baseline to an economy-wide target would be subject to this procedural change.

\section{National sectoral baselines}

If countries do not seek result-based payments, existing arrangements for technical analysis through ICA would be sufficient as agreed at the COP in Warsaw 2013. If countries seek results-based payments they 
could submit a supplementary technical annex for consideration in ICA. If countries will generate tradable units to meet international emissions reduction commitments, verification efforts and stringency would increase, and the technical annex in sectoral emissions reductions submitted attached to the BURs and aligned with a reporting format as in BRs would be subject to ICA or IAR.

Each country using a sectoral approach to generate transferrable units would need to prepare true-up period reports at the end of each agreed commitment period to report on the utilization, transfer and retirement of emissions reduction units subject to Expert Review Team (ERT) and Compliance Committee, if emissions reduction units are transferred.

An additional verification process could be used for countries that participate in market-based approaches. Thereby additional verification executed by domestic or internationally accredited third parties would be subject to third party verification

\section{Subnational sectoral mitigation actions}

For countries with subnational sectoral baselines, emissions reductions would be reported in national communications and BURs on the progress achieved towards national sectoral baselines or economy-wide emissions reduction targets, subject to ICA. If these activities are market-based, verification of these activities would be subject to accredited third parties akin to the Designated Operational Entities (DOEs) of the CDM.

\section{Policies and Measures}

Verification of the 4 yearly national inventories and national communications would follow reviews by the Expert Review Team (and Consultative Group of Experts) and verification of BURs would use the existing International Consultation and Analysis (ICA) system. 
Table 6 - Options for verification of land use in a post-2020 framework

\begin{tabular}{|c|c|c|c|c|c|}
\hline Option & $\begin{array}{l}\text { Common } \\
\text { objectives }\end{array}$ & Objective & Frequency & Actor & Process \\
\hline $\begin{array}{l}\text { Economy- } \\
\text { wide } \\
\text { targets }\end{array}$ & $\begin{array}{l}\text { Review every } 4 \\
\text { years by Expert } \\
\text { Review Teams } \\
\text { (ERT) and } \\
\text { Consultative } \\
\text { Group of Experts }\end{array}$ & $\begin{array}{l}\text { Alignment of frequency } \\
\text { and quality and for- } \\
\text { mats. For countries } \\
\text { with sectoral ap- } \\
\text { proaches every } 2 \text { years. } \\
\text { Convergence between } \\
\text { IAR and ICA. Review by } \\
\text { CGE or ERT of aligned }\end{array}$ & $\begin{array}{l}\text { Annually and } \\
\text { every two } \\
\text { years }\end{array}$ & ERT & $\begin{array}{l}\text { Initial check to verify completeness and } \\
\text { correct format. Compilation of basic } \\
\text { information across Parties and assess- } \\
\text { ment of individual Parties' inventories. } \\
\text { International ERTs examine the data, } \\
\text { methodologies and procedures used in } \\
\text { preparing the national inventory. }\end{array}$ \\
\hline $\begin{array}{l}\text { Sectoral } \\
\text { targets }\end{array}$ & & BUR/BPs & Every 2 years & ERT & $\begin{array}{l}\text { For results-based payments ICA of BURs } \\
\text { with an additional review of supplemen- } \\
\text { tary information in form of a Technical } \\
\text { Annex on reference levels, national } \\
\text { forest monitoring systems or agricultural } \\
\text { NAMA monitoring system and activities } \\
\text { +achieved GHG emissions reduc- } \\
\text { tions(based on tier } 2 / 3 \text { ) to the BUR. } \\
\text { For internationally fungible units the ICA } \\
\text { process could be change to IAR reported } \\
\text { in standardized formats (e.g. CTF). In } \\
\text { case of market-based approaches } \\
\text { accredited third party verification bodies } \\
\text { could be used. }\end{array}$ \\
\hline $\begin{array}{l}\text { Sub- } \\
\text { national } \\
\text { baselines }\end{array}$ & & $\begin{array}{l}\text { If sub-national pro- } \\
\text { ject/programme GHG } \\
\text { emissions reductions } \\
\text { are transferred be- } \\
\text { tween countries to } \\
\text { meet GHG reduction } \\
\text { commitments, verifica- } \\
\text { tion by accredited third } \\
\text { parties based on } \\
\text { project/programme- } \\
\text { based monitoring } \\
\text { systems }\end{array}$ & $\begin{array}{l}\text { At least } \\
\text { every } 5 \text { years }\end{array}$ & $\begin{array}{l}\text { Designated } \\
\text { Operational } \\
\text { Entities (DOEs) }\end{array}$ & $\begin{array}{l}\text { Undertakes an assessment of the } \\
\text { monitoring report as outlined in the } \\
\text { project design document (PDD) including } \\
\text { site visits of the projects. Verify that } \\
\text { monitoring methods are applied consist- } \\
\text { ently and in compliance with the meth- } \\
\text { odologies and verify the actual emissions } \\
\text { reduction/carbon removals have oc- } \\
\text { curred. }\end{array}$ \\
\hline $\begin{array}{l}\text { Policies } \\
\text { and } \\
\text { measures }\end{array}$ & & $\begin{array}{l}\text { Review of National } \\
\text { Communications and } \\
\text { IAR of BURs }\end{array}$ & $\begin{array}{l}\text { Every } 4 \text { years } \\
\text { for } \mathrm{NC} \text { and } 2 \\
\text { years for } \\
\text { BURs }\end{array}$ & $\begin{array}{l}\text { SBI and techni- } \\
\text { cal experts }\end{array}$ & $\begin{array}{l}\text { The ICA for BURs coordinated by SBI. } \\
\text { Technical experts in consultation with the } \\
\text { Party will analyze the transparency of } \\
\text { mitigation actions and their effect and } \\
\text { produce a summary report. }\end{array}$ \\
\hline
\end{tabular}




\section{Country positions}

With negotiations on a post-2020 framework still at a relatively early stage, the majority of submissions and discussions have focused on the broad questions of how an agreement will be framed and Parties' overall contributions agreed upon. Specific discussion of issues regarding the role of the land-use sector has been limited. Indeed, some countries have indicated that they would prefer for negotiations on the land-use sector to begin only after "the framework of the 2015 agreement is clear." 99 Similarly, representatives of the Philippines have indicated in interviews that the majority of rules on land-use will be negotiated after 2015, with a 2015 agreement being limited to setting out the basic framework of a land-use system. ${ }^{100}$ At the same time, the general discussions themselves provide a range of important insights into the overall role of the land-use sector in a post-2020 agreement.

The views of Parties referred to in this section are for the most part drawn from their submissions under the various negotiation tracks of the UNFCCC. Given the large number of submissions that are referred to throughout the text, for convenience the authors have not included footnotes each time a Party's view is referred to; instead, a list of submissions that were used for this chapter, divided by topic, are provided in Annex I. The authors have also drawn on Parties' submissions under Appendices I and II of the Copenhagen Accord. Though few developed countries provide detail on the role of agriculture, forestry or land-use (collectively referred to as AFOLU in this chapter) in their pledges under Appendix I, many developing countries provide relatively detailed information on the role of AFOLU in their pledges, which may be instructive in considering the contributions they are willing to assume under a post-2020 framework. Tables summarising the AFOLU-relevant compo-

${ }^{99}$ Statement of US representative at High-level panel event on the land sector and forests, Warsaw, Monday 18th November 2013. See Lindsay Speer, "More on the High Level Panel Event on the Land Use Sector and Forests" Vermont Law School Blog, available at: http://vlscop.vermontlaw.edu/2013/11/19/more-on-thehigh-level-panel-event-on-the-land-use-sector-and-forests/

100 Interview with Tony la Viña, Warsaw, November 2013. 
nents of the submissions of developing countries are included in Annex 2 to this report.

\subsection{Differentiation between countries}

For the most part, Parties' submissions appear to recognize that a range of different types of contributions will exist in a post-2020 framework. A range of submissions identify types that closely correspond to one or more of the four overarching options identified in section 4.1, though some are reflected more widely than others:

- National or sectoral targets. On one hand, there is broad recognition of the role of national targets, which are specifically identified in, among others, submissions of China, India, the EU, Japan, USA, the like-minded developing counties ( $L M D C S$ ), $L D C s$ and the African Group. All pledges of developed countries under the Copenhagen Accord and a small number of developing countries have taken the form of national targets. For the most part, the specific role of the land-use sector has not been addressed by countries submitting national targets, though Russia, Belarus and New Zealand have emphasized the need for clarity on LULUCF accounting rules in implementing their targets. Fewer countries have specifically identified the possibility of sectoral targets, though this option is highlighted by the USA.

- National or sectoral baselines. National baselines are also identified in several submissions, including those of the African Group, $L D C s$, the $E U$, and the USA. Other Parties, such as China and India, refer more broadly to "enhanced mitigation actions" and NAMAs, respectively. If seen in terms of those countries' voluntary 2020 pledges, this could be interpreted to include national baselines or emission intensity targets, which have been pledged by a large number of advanced developing countries. In several cases land-use measures have been specifically identified as forming part of these pledges, while no Parties have specifically sought to exclude the land-use sector from these targets. Sectoral baselines, meanwhile, are widely discussed in the context of REDD+. Under the Copenhagen Accord, two Parties submitted pledges targeting zero deforestation, at least within a given type of forest or geographical area, and others expressed targets relating to area under forest cover. In contrast, in the context of agriculture the majority of developing countries are strongly 
opposed to any form of sectoral mitigation commitments, and no sectoral pledges regarding agriculture were submitted under the Copenhagen Accord.

- Project approaches. A significant number of Parties have supported the inclusion of additional land-use activities under the clean development mechanism, though there remain some Parties that are opposed to the expansion of market-based mechanisms. Among those countries supporting additional activities, differences exist as to the scope of new activities to be included. The Congo Basin countries (COMIFAC) for example support the inclusion of a broad scope of activities, while the $L D C s$ suggest only two new activities (improved cropping, and revegetation) and China states that the focus should remain on afforestation and reforestation, though some new activities could be considered. Several other countries have not taken a firm view on the scope of activities to be included, stating that more consideration is needed.

- Policies and measures. Several submissions - including those of the $U S A$, the $E U$ and $L D C s$ - directly identify the policies and measures among types of contributions Parties may assume, while a range of other Parties refer to terms such as NAMAs and "enhanced mitigation actions" that would appear to encompass this option. Moreover, the concept of NAMAs is firmly entrenched in UNFCCC decisions, indicating an important role for policies and measures. The pledges of the majority of less developed countries under the Copenhagen Accord have consisted primarily of policies and measures, and a large number of these included policies and measures in the land-use sector. Several of these were quantified, either in terms of GHG emissions reduced or avoided or in terms of hectares targeted by measures. The majority, however, have not been quantified.

\subsubsection{Determining which option applies}

While the four types of contributions are broadly recognized, divergence remains over whether common rules or principles should determine which type of contribution each Party assumes and, if so, what those common rules or principles would be.

With respect to the first question, Parties agreed in Warsaw that contributions should be nationally determined, but did not agree on the use of common metrics for determining them. Several Parties have put forward suggestions for this approach. The African Group, for example, has suggested a "principle-based framework" based on the required global effort 
and Parties' historical responsibility, current capability, and development needs, while Brazil has suggested the development of metrics based on historical responsibility. The USA, by contrast, does not support an approach based on formulas or involving categories of Parties, but rather on a more flexible approach based on national circumstances. Under this concept Parties could choose a combination of approaches, such as a cap for one sector, an intensity target for another, and policies for another.

Other Parties and groupings have expressed more specific views on the types of contributions certain types of Parties should assume. Most major developing countries and developing country groupings - including China, India, the like-minded developing counties (LMDCs), LDCs and the African Group - take the view that all Annex I Parties must assume absolute, economy-wide emission targets. This view is also reflected by several developed Parties, such as the EU, while Japan refers to all "major economies" taking on such targets.

There is less support for international rules on the type of contributions to be assumed by developing countries, particularly among developing countries themselves. The $L M D C s$ reject any role for ex-ante definition of what developing counties should contribute, and view it as "inevitable" that they will vary in nature and type. The $L D C$ s take a more nuanced view, arguing that "various types of commitments, such as absolute targets, relative targets, policies and regulatory instruments, should accommodate various capabilities and vulnerabilities", and allow for some degree of differentiation for emerging economies, middle-income countries and $L D C s$. The African Group, meanwhile, supports non-Annex I Parties taking on mitigation actions in accordance with their current capabilities that support a deviation from business-as-usual, though it is not specified if these should take a given form. The EIG calls for the type and stringency of contributions to reflect, inter alia, "changing economic realities" and be based on a common international understanding of fair differentiation. The $E U$ is more direct, stating that both Annex I Parties and "other Parties with the greatest responsibilities and capabilities" should take on economy-wide targets, though it indicates that these could be based on baselines as well as targets. As noted, the USA favors flexibility for countries to determine their own types of contributions.

\subsubsection{Graduating between options}

Various Parties have expressed the view that countries could "graduate" from one form of contribution to another. The $E U$, for example, believes that all Parties should aspire towards eventually having economy-wide 
absolute targets, while in the context of markets Parties should move from CDM to sectoral approaches to economy-wide cap-and-trade. Similarly, the $L D C s$ view that developing countries' commitments could move from relative targets to absolute net reductions "at the most appropriate development levels and time", while a similar view is taken by South Africa. Other countries, including Ethiopia, Australia and the USA refer more generally to raising ambition over time in accordance with changing circumstances, which may be understood to include graduating to more absolute contributions.

Many Parties who advocate graduation over time emphasize the need for the system to facilitate this transition without the need to repeatedly re-negotiate targets and rules, and New Zealand emphasizes this with respect to the land-use sector in particular. This would appear to point to land-use sector accounting frameworks that are designed to provide for a certain level of consistency between approaches so that transitions can be managed smoothly such as, for example, aligning key concepts and approaches in measurement and reporting frameworks.

\subsubsection{Compliance}

Parties broadly agree on the need for a post-2020 framework to include some form of compliance mechanism. India supports the development of a compliance system with a differentiated structure for Annex I and nonAnnex I Parties, with the former subject to compliance and consequences for breaches, while the latter are encouraged to remain in compliance through a set of incentives. This separation between compliance for developed countries and incentives for developing countries is echoed by several other developing countries. In contrast, the EIG supports the application of a compliance regime to all countries, while the LDCs indicate that broad rules on compliance should be adopted, though more stringent rules would apply to developed countries, being at least as stringent as the existing rules under the Kyoto Protocol.

\subsubsection{Sectoral market approaches in the land-use sector}

The extent to which market approaches will play a role under each of the four options set out above is an important factor in terms of accounting. In the case of most of the options, discussions on this issue remain in early stages. With respect to absolute, economy-wide targets few Parties, with the exception of the $L D C s$, have expressly set out whether they are in favor of these targets being tradable, though the USA and the EU 
have strongly implied they would be. At the same time, many Parties have indicated that the new agreement should build on existing agreements, perhaps implying that the trading infrastructure of the Kyoto Protocol would be preserved.

The issue of sectoral market approaches for the land-use sector, in particular in the context of REDD+, has long been contentious. In Warsaw, Parties agreed to rules on REDD+ that did not include a market approach but emphasized that this did not pre-judge the outcome of discussions on the new market-based mechanism or the framework for various approaches, appearing to shift focus on sectoral market-based approaches for the land-use sector to these fora. ${ }^{101}$ While the NMM is still under development, current proposals identify the possibility for both crediting and trading, hence inclusion of the land-use sector could see market based approaches under both options 1 and 2 .

Views on whether land-based activities should be eligible under the NMM or FVA remain divergent. The Coalition for Rainforest Nations has specifically advocated the inclusion of REDD+ under the NMM and Indonesia has said that the FVA should include REDD+ or landscape-based approaches, while the USA has said REDD+ should be incorporated within these processes "to the extent possible and as appropriate" and the EU has indicated that all sectors and sub-sectors included in Parties inventories should be included, which includes both agriculture and LULUCF. Norway has stated, more generally, that at least any trading track should be limited to sectors where Parties have in place systems "necessary to trade under a binding cap." In contrast, AOSIS has expressed specific opposition to the inclusion of REDD+ under the NMM, while the $L D C s$ view the NMM as limited to trading of economy-wide targets.

More generally there are certain Parties, most notably Bolivia, which are opposed to the very idea of markets and have consistently argued against their use under the UNFCCC. Other countries such as Brazil and AOSIS have expressed opposition to the use of markets in the context of land-use activities.

101 Decision -/CP.19, paragraph 18. 


\subsubsection{Integrating adaptation and mitigation}

Though not widely addressed in Parties' submissions, a number of Parties, including the Philippines, Bolivia, and Gabon, together with several EU Member States have expressed during informal meetings that a post2020 land-use framework should address both adaptation and mitigation. ${ }^{102103}$ Bolivia in particular has been a strong advocate of this approach, proposing a Joint Mitigation and Adaptation Mechanism that would use non-market based finance to support developing countries in implementing actions that address both mitigation and adaptation. Methodologies would be based on the ecological stability of forests and forest landscapes and indicators that jointly address mitigation and adaptation would be used to measure success. 104

The majority of developed country Parties - including Japan, Canada, the EU, Australia, New Zealand and the USA - have also stressed the need to consider adaptation and mitigation in an integrated manner in relation to agriculture. Many developing countries however, have expressed their reluctance to consider mitigation within any UNFCCC discussions on agriculture. This appears to arise mostly out of the concern that such discussions could lead to the introduction of sectoral mitigation targets for developing countries, which could threaten livelihoods and food security, as has been expressed by, for example, India, the Philippines and Argentina in the Bonn negotiations in 2013.105

Nonetheless several developing countries, including Bangladesh, the Independent Alliance of Latin America and the Caribbean (AILAC) and the African Group have expressed support for looking at both adaptation and mitigation under agriculture. In this context it is conceivable that there may be broader support for addressing both aspects in a more integrated manner provided that, in the context of developing countries at least, such efforts are focused on supportive measures and do not involve the introduction of any form of mitigation commitments. Indeed, the majori-

\footnotetext{
102 The EU Member States in question are Portugal, Lithuania, Ireland and Austria. It is important to note here that in the UNFCCC the EU speaks with one voice, and hence these views should not be considered as formal positions of these countries under the UNFCCC. Nonetheless, they are relevant to considering the prevalent views within the EU. 103 Ibid.

${ }^{104}$ Submission by the Plurinational State of Bolivia on the Development of the Joint Mitigation and Adaptation Mechanism for the Integral and Sustainable Management of Forests, 28th February 2012, available at: http://unfccc.int/documentation/submissions_from_parties/items/8017.php 105 See IISD, Earth Negotiations Bulletin, Warsaw Highlights: Tuesday, 12th November, available at: http://www.iisd.ca/download/pdf/enb12585e.pdf
} 
ty of recent submissions on agriculture have focused on information sharing and knowledge development, capacity-building and technology development and transfer. This suggests that any specific efforts to address mitigation in the agriculture sector under the UNFCCC will remain focused on supportive measures and will not lead to accounting for agriculture emissions in developing countries. On the other hand, it remains conceivable that the agriculture sector will be accounted for under any economy-wide targets or baselines that are assumed, including by developing countries.

\subsection{Accounting}

\subsubsection{Integration of accounting frameworks}

Discussions on whether and how accounting frameworks should be more integrated remain at early stages, and the issue is not under specific consideration by any of the negotiation bodies. Some Parties, such as Bolivia, Papua New Guinea, Mexico and New Zealand, together with several EU Member States, 106 have expressed the need for "holistic" approaches to land-use under a 2020 agreement in informal meetings, but have not set out the details of how this would be achieved.107 In informal negotiations one EU Member State has also highlighted the importance of linking the land-use sector with other sectors, such as the energy sector, in particular with regard to biofuels. ${ }^{108}$ At the same time, several Parties have used the opportunity of the SBSTA's work programme on ways to achieve more comprehensive accounting of LULUCF (hereinafter, the "SBSTA work programme") activities to discuss this issue, despite it technically being framed in terms of LULUCF under the Kyoto Protocol, and thus with respect to Annex I Parties only. For example:

\footnotetext{
106 The Member States in question are Lithuania and Portugal.

${ }^{107}$ See Lindsay Speer, "More on the High Level Panel Event on the Land Use Sector and Forests" Vermont Law School Blog, available at: http://vlscop.vermontlaw.edu/2013/11/19/more-on-the-high-level-panelevent-on-the-land-use-sector-and-forests/. The Member State in question is Sweden. 108 Ibid.
} 
- The $E U$ has argued that the work programme could inform the discussions under the ADP process on the post-2020 agreement and therefore would like to include all parties in discussions. In addition, EU representatives have expressed in interviews that the EU is seeking to address land-use under the UNFCCC in a comprehensive, wall-to-wall, fashion rather than in terms of the specific mechanisms or negotiation tracks. ${ }^{109}$

- The EIG has argued that technical work must be advanced towards a common accounting framework for land-use under the 2015 Agreement.

- Both the African Group and COMIFAC support rules on compatibility in LULUCF that are applicable to all parties, but take into account Parties' national circumstances and provide for support for developing countries to adapt to them.

- Indonesia has stated that the various work programmes relating to land-use should address issues the consistency of different accounting approaches, both in developed countries and in developing countries.

- New Zealand has suggested looking for synergies/compatibility between how different land types are currently treated under different tracks and considering whether specific land-use types could be considered equally regardless of where they are (e.g. in developed or developing countries).

- Japan has stated that LULUCF accounting methodologies should be applicable to all parties post-2020.

These views indicate that there is general support for at least ensuring compatibility between the different accounting frameworks for the landuse sector, and perhaps integrating them into a single coherent framework. On the other hand, the $L M D C$ s have expressed strong opposition to common accounting frameworks for developed and developing countries more generally, which may present challenges with respect to LULUCF. It is also worth keeping in mind that any attempts at integration will need to grapple with the different stages of development of the existing frameworks. While Parties have now begun to consider the reform of LULUCF under the SBSTA work programme for example, thereby making that track amenable to greater integration with other frame-

109 Interview with Michael Bucki in Warsaw, November 2013. 
works. Parties in Warsaw just finalized many years of difficult negotiations on the framework for REDD+, which may make any attempts to open discussions on those rules politically challenging.

Finally, it is worth noting that not all Parties support discussion of this issue under the SBSTA work programme. China has emphasized that discussions on more comprehensive accounting should focus on Kyoto and not address the post-2020 framework, since this will distract from technical discussions and would pre-judge other negotiations.

\subsubsection{Framework for Various Approaches}

The Framework for Various Approaches (FVA) is understood by many Parties as a means of developing common standards or principles for mitigation approaches, and Parties such as AOSIS go further, advocating the FVA to set a single set of rules. Parties such as the USA and Australia, on the other hand, see the framework primarily as a platform for information sharing on mitigation approaches. Parties in favor of principles, standards or rules have suggested that these might cover aspects such as measurement and reporting requirements, verification processes, core characteristics of units, requirements around baselines and net mitigation of offset mechanisms. Many Parties also advocate that the FVA should establish a central tracking infrastructure to monitor the trade in and avoid double counting of units and outcomes.

Few Parties have specifically addressed whether the FVA should encompass land-based activities. Of the few Parties that have addressed this issue, the Coalition for Rainforest Nations and Indonesia have specifically indicated that they support land-based activities (specifically REDD+) being covered by the framework, while Bolivia has indicated that its proposed mechanism on Joint Mitigation and Adaptation for the Integral and Sustainable Management of Forests should be included within the FVA. At the same time, many Parties agree that the FVA should at least cover existing approaches under the Convention and Kyoto Protocol, such as the CDM and international emission trading (IET), which currently cover land-use activities.

To the extent that the FVA does cover land-use this could have a significant impact on the design of accounting and MRV frameworks for the land-use sector. The potential exists for the FVA to establish an overarching framework that could ensure some level of compatibility and consistency among the various land-use tracks under the UNFCCC and potentially also outside the UNFCCC. The establishment of a trading or tracking infrastructure and common approaches to double-counting 
could also provide an important means of providing against doublecounting among the different tracks. Given the unique characteristics of the land-use sector it is likely that a separate set of standards or rules may need to be developed; however, there remains no discussion of such details as of yet.

\subsubsection{Balancing simplicity and flexibility}

One of the key challenges on creating a more integrated comprehensive system that appears to emerge from Parties submissions is how to create a system that is at once simple and manageable and at the same time accommodates Parties' heterogeneous national circumstances. Both these goals were emphasized by a range of Parties and certain Parties, for example New Zealand, have recognized the challenge that these dual goals raise. The extent of this challenge is evident from the experience of the Kyoto Protocol - where, as described above, the attempt to accommodate a range of Party-specific circumstances led to an incredibly complex and difficult set of rules being created - and is arguably heightened in a system that seeks to bring developed and developing countries under a single framework.

Though little discussion of how this challenge could be addressed has thus far taken place, some Parties have begun to touch on the issue in their submissions under the SBSTA work programme. The African Group has suggested the use of different accounting categories, tiers and scales for different countries but within a single system and for capacitybuilding to be provided to enable developing countries implement comparable accounting to developed countries. The $E U$ suggests a step-wise approach involving mandatory accounting for all land-use categories and land-use changes, except categories where experience with existing methodologies are less developed or where there is a lack of data, which would become mandatory over time. New Zealand, for its part, suggests that flexibility within a single system can be provided for by allowing for prioritization according to key source/sink activities or domestic land management practices, or through providing mechanisms to account for high levels of natural disturbances or different forest growth rates. New Zealand also echoes the African Group's support for using different tiers, with progressive evolution from lower to higher tiers. 


\subsubsection{More comprehensive accounting}

The recognition by Parties of the need for more comprehensive accounting for the land-use sector is clear from the establishment of the SBSTA work programme. For the most part, Parties' submission on this issue are framed in terms of exploring the issue further and setting out relevant issues rather than taking a firm position, reflecting the complex nature of this subject. Several Parties including Japan, China, the EU and New Zealand, consider that more comprehensive accounting can be achieved through either land or activity-based accounting, depending on how they are designed, though there appears to be a recognition that any activity-based system would need to provide for greater compulsory inclusion of activities. In this respect, several countries, including Australia, New Zealand and the EU particularly highlight the importance of accounting for harvested wood products, while Belarus has emphasized that soils and wetland and peatland rewetting should be included. Japan favors allowing for both approaches, depending on national circumstances. Other Parties, such as Pakistan, Malaysia and the African Group, express a preference for a land-based approach, though not ruling out an activity-based approach where this is not feasible.

Australia suggests an alternative approach that would "nest" an activity-based emissions accounting approach within a comprehensive landbased reporting system. This system accommodates countries such as Australia which have a large land mass and extensive areas of land that are not under active management, since only lands under active management are accounted for. Australia does recognize, however, that this approach risks leading to a less than comprehensive coverage even of managed lands. To compensate for this it suggests that there may be merit in examining new accounting approaches for various activities as was developed for forest management in the Kyoto Protocol's second commitment period. New Zealand also identifies a similar combined approach as a possible option, noting the differences in the purpose of reporting and accounting. However, it does not express a clear preference for any particular accounting approach at this point.

A number of Parties have stressed that even a comprehensive accounting system should focus on managed lands and human-induced changes, including China, the EU, Australia and New Zealand, and New Zealand further points to the need to focus on land or activity types that are most amenable to policy influences. Some countries also put forward strategies to achieve this. Australia suggests allowing optional exclusion of certain land areas upon verification that such areas are not subject to 
active management, as well as maintaining the Kyoto Protocol rules on natural disturbances.

\subsubsection{Baselines}

Few Parties' submissions have so-far touched upon approaches to setting baselines for land use in a post-2020 framework, beyond the more general discussion on the respective types of overall contributions that Parties should undertake (e.g. targets vs. deviations from business-asusual) discussed in section 5.1 above. Australia has expressed its support for retaining the forest management reference levels adopted under the Kyoto Protocol's second commitment period and is in favor of considering their potential expansion to other accounting categories. Both the EU and New Zealand have also indicated that they are in favor of exploring the potential for expanding reference levels to other categories, though the $E U$ notes that it is challenging to establish reference levels for all land-use categories. As such, the $E U$ suggests that the use of reference levels for some activities or lands and the use of net-net or gross-net accounting for others could be considered. The $E U$ also notes that on the whole Parties do not consider unconstrained gross net accounting as a possible accounting option.

\subsubsection{Permanence}

At present, the only land-use negotiating track that is currently discussing the issue of permanence is the SBSTA work programme on addressing the risk of non-permanence under the CDM. In this context, most countries are in favor of the creation of permanent credits and have suggested a wide range of approaches to address permanence, including buffer accounts, insurance, and guarantees being provided by host countries, including within the framework of national or sub-national REDD+ programmes. Buffer accounts are perhaps the most widely cited option. In addition, China has suggested that projects with lower risks should be prioritized, and that permanence risks should be shared between developed and developing countries.

As discussed in Section 2.3.1 over, permanence under the Kyoto Protocol is largely unaddressed, and no discussion of how permanence would be applied to economy-wide targets or sectoral baselines post2020 is currently taking place. 


\subsection{Measurement and reporting}

While specific discussion around measurement and reporting of land-use in a post-2020 framework remains limited, some general principles are discussed under the SBSTA work programme on comprehensive accounting.

Some Annex I Parties are in favor of integrating the existing LULUCF measurement and reporting framework into a post-2020 land-use framework for all countries (EU, Japan, Australia, New Zealand, and Russia). Also the African group is in favor of developing common measurement and reporting rules - within the context of common accounting frameworks - but with different tiers and categories for countries with lower capacities. AILAC, on the other hand, is strongly opposed to merging the separate reporting tracks for developed and developing countries, viewing it as "not conceivable that the onerousness of the responsibility of Non-Annex I should be the same as Annex I."

Below we summarize the key positions of the countries related to the four key characteristics of measurement and reporting.

\subsubsection{Approach to measurement and reporting}

Discussions on whether to adopt an activity or land-based approach are at a very early stage. Most countries do not have a determined position on whether to adopt a land-based or activity-based approach and are currently seeking more technical analysis of the approaches and a better elaboration of the implications of each approach. In general, their considerations relate to the following issues:

- The EU, New Zealand, Japan and China have stressed that no matter which approach is taken, the approach should provide incentives for sustainable land-use management and maximize the mitigation potential of LULUCF.

- The EU, Australia, China, Japan, and New Zealand stress that the approach taken should be as simple as possible, and should build on the extensive work undertaken under the Kyoto Protocol.

- According to Australia, a technical analysis of "linkages between categories and activities, the sources of differences, and similarities" should be undertaken, and more consideration given to operating a single approach when developing national inventory systems as compared to current separation of reporting for the Convention (land-based) and accounting for Kyoto Protocol (activity-based). 
- The $E U$ also suggested that if a land-based approach is adopted, reporting should be based on existing reporting tables for national reporting requirements under the Convention, thus indicating that continuity with existing requirements is desirable.

\subsubsection{Coverage}

Considering that most countries have limited capacities and varying national circumstances, countries' submissions emphasize an inclusive and simple approach. Issues raised include the following:

- Countries with large land masses, such as Australia, Russia, China, advocate for an approach that distinguishes between managed and unmanaged land, suggesting that managed land can be used as a proxy for human-induced land-use activities and related GHG emissions, emissions reductions and removals. Australia has proposed a nested approach in which countries measure and report on their entire land area, while accounting is undertaken only for managed lands.

- The EU's position is to account for all pools and gases (including HWP), where robust and accurate data and methodologies are available, and to encourage Parties to continuously improve their measurement reporting capacities, gradually moving to higher tier methodologies.

- According to New Zealand's submission, Kyoto Protocol LULUCF measurement and reporting provided insufficiently comprehensive coverage of emissions, and proposes a bounded flexibility for domestic policy design that allows prioritization according to key source/sink activities, or domestic land management practices. The system would be readily applicable by all countries and types of economies, setting out "common approaches which could be sufficiently simple and flexible to be able to be applied consistently to all forests or all lands, in countries at all stages of development." The principles underlying this proposal focus on maximizing future participation in land-use sector mitigation and flexibility for Parties to accommodate their national circumstances, while scaling up completeness, coverage and accuracy over time, as ambition and national capabilities permit. Russia has also advised to take into account current decisions and further negotiations under REDD+ and NAMAs in order to achieve a wider coverage of participation in the global agreement after 2020 . 


\subsubsection{Uncertainty}

All countries are aware of the complexities and uncertainties related to land-use measurement and reporting, and the different circumstances and capacities to undertake measurement and reporting on land use. Some countries have stressed the relevance of allowing different tiers with a graduation as capacities increase.

- New Zealand proposes to ensure environmental integrity by recognizing progressive improvement of measurement and reporting, taking into account national circumstances, by identifying key category analysis as a starting point, "to establish significance, materiality, and allow prioritization and the provision for progressive evolution and improvement from a Tier 1 to Tier 3 approach reducing uncertainty over time." It also proposes the differentiation between mandatory and elected activities, ensuring that key land-uses are accounted for, while maintaining the incentives to improve over time on other land uses.

- The African Group's submission suggests that there "should be a systematic approach for countries to be in different accounting categories/tiers (this might include project scale for developing countries versus land-based accounting for developed countries)." On the other hand, some countries have suggested simplification of measurement and reporting systems as an approach to addressing differences in country capacities.

- Russia and the EU have proposed that reporting complexities should be reduced as far as possible and further consideration should be given to simplifying measurement and reporting systems, while maintaining robustness of the systems.

\subsubsection{Comparability}

The need for consistency and comparability over time is recognized in several Parties' submissions. The alignment between the requirements of measurement and reporting under the Kyoto Protocol and a post2020 measurement and reporting framework is identified as a key issue, with most Parties stressing the need for continuity. 
- According to EU, Australia, China, Japan, and New Zealand, the post2020 land-use framework should maintain consistency and comparability between Kyoto reporting and a post-2020 framework and allow for the utilization of existing national inventory systems established for LULUCF accounting under Kyoto Protocol (Japan) or other national data collection systems (China).

- New Zealand expressed preference for ensuring comparability, to the extent possible, over time and between Parties, and Japan stated that consistency and continuity is one of the underlying principles of GHG inventories, and gaps between LULUCF reporting and accounting between pre- and post-2020 should be minimized to the extent possible and "simple and practicable guidance should be given how to address this issue, possibly by recalculation or well-documented explanation about the gap by Parties."

- Russia stated that, given the considerable experience gained by Annex I Parties and the degree of established systems, it will be necessary to ensure the continuity of the methodological principles and approaches and maintain comparability and consistency across time series, and it is appropriate to retain established systems for reporting of second period Kyoto Protocol baselines considering possible technical corrections to them.

- China has proposed an inclusive approach that gives due consideration of different national circumstances. Any approach taken should be as simple as possible, improve data collection and availability and methodologies and maintain consistency and comparability between reporting under the Convention and the Kyoto Protocol.

\subsection{Verification}

Discussions on the specifics of a verification and compliance system under a post-2020 regime remain in their early stages. Most likely they will build upon the existing ICA and IAR processes. For both approaches the objectives and modalities have been agreed at the COP 17 on the International Consultation (ICA) process for developing countries and International Assessment and Review (IAR). It was agreed that a review of both processes will be undertaken after the first round of submissions. For ICA at COP 17 (Durban, 2011)) it was also agreed that a review of procedures and modalities should take place after the first round of submissions and reviews no later than in 2017. IAR Parties agreed that modalities and procedures will be revised no later than 2016 (COP 
22), after experience from the first round reviews. Thus there are currently no ongoing political negotiations on the objectives of both verification streams under the UNFCCC.

Nevertheless, Parties have begun to express views on general principles for the systems that should apply to developed and developing countries.

- Several countries and groupings (e.g. AILAC) express broad support for the continuation of the systems of IAR for developed countries and ICA for developing countries. The $E U$ is less clear in its views, saying only that the new system should build on the experience with the current MRV regime, including IAR and ICA.

- Other Parties have more broadly supported differentiation in verification requirements, with Australia stating that requirements should include "necessary flexibility to accommodate differences in capacity."

- Japan appears to favor differentiation based more on a country's emissions rather than capacities.

\subsubsection{Frequency}

In the framework of the SBSTA work programme on the revision of the guidelines for the review of biennial reports, national communications, including national inventory reviews in accordance with decision 1CO16 (paragraph 46(b)), New Zealand and the USA expressed desire for a reduction in the frequency of an annual inventory review for developed countries to a biennial review, while GHG inventory reporting should remain on an annual basis (with half of the Annex I Parties reviewed each year). New Zealand and the USA suggest that over the past decades Parties GHG inventories have undergone significant improvements and most meet the quality standard of UNFCCC/Kyoto Protocol, and IPCC good practice guidance. They also argue that the "current system where many review reports are only finalized two or three months before the next national inventory report is submitted does not give the Party enough time to follow through on recommendations from the previous review." In addition, since the ICA process will draw from the same pool of experts, this will require significant additional capacities, and the biennial review process would free up capacities for ICA starting in 2014. 


\section{Conclusion}

Land-use emissions are responsible for about a quarter of global GHG emissions; 110 a source of emissions too important to be treated as a second-tier priority in international negotiations. While the UNFCCC assigns equal importance to anthropogenic emissions from all sources and removals from sinks, the Kyoto Protocol to date has primarily incentivized reductions in emissions from industry and energy generation, while treating the land-use sector as little more than an accounting loophole.

During negotiations of the Kyoto Protocol, the consideration of forestry and land-use emissions became discredited to such an extent that it was suggested that anybody who favored sinks was not genuinely concerned about climate change. ${ }^{111}$ For many NGOs and (mainlyEuropean) negotiators the matter of sinks became a distraction from the main goal of climate policy: the reduction in the use of fossil fuels. Consequently, the agreement on forest emissions and removals under the Kyoto Protocol came late and as an add-on to the agreement on overall emission caps. Rather than forming part of the main package of emission reductions and limitation commitments, LULUCF was used as a negotiation token adding flexibility where needed to bring countries along to support the overall deal.

Developing country land-use mitigation also fared poorly under the Kyoto negotiations. Due to concerns over permanence and leakage, reinforced by the understanding that developing countries generally lacked the capacity to measure and report land-use emissions, land-use mitigation was essentially excluded from the Kyoto Protocol.

Today, more than 15 years after the adoption of the Kyoto Protocol, the treatment of land-use emissions under a future climate treaty remains a complicated topic. On the one hand, it is even clearer now than in 1997 that omitting sinks from a climate deal would exclude one of the most important sources of emission reductions and removals from a

\footnotetext{
110 Tubiello, F. et al. The FAOSTAT database of greenhouse gas emissions from agriculture. 2013. Available from: http://www.fao.org/climatechange/36143-0fa4483057747f41c08183b702ec5954e.pdf 111 Streck and Scholz, 2006, The role of forests in global climate change: whence we come and where we go. Foreign Policy.
} 
future climate treaty; on the other hand, a post-2020 climate agreement is likely to create a far more differentiated and diverse set of targets and commitments across Parties making the integration of sinks even more of a challenge than before.

The main constraints for land-use mitigation in the context of a future climate treaty can be summarized as follows:

- While there is general agreement that all countries have to contribute to climate change mitigation according to their common but differentiated responsibilities and respective capabilities there continues to be disagreement about the distribution of the mitigation and financing burden across Parties. These disagreements, however tend to be much more relevant in the area of energy and industry than in discussions around land-use emissions.

- Given the relevance of the agricultural sector for many countries and its close links to food security, there is still controversy around the role of agricultural mitigation under the climate regime versus a consideration of agriculture for climate change adaptation purposes only. Negotiations on agriculture have been burdened with misunderstanding and concerns about competitiveness and trade implications, and are less advanced than forestry.

- While negotiations on REDD+ are comparatively advanced, discussions to date have largely focused on the technical components of forest-based mitigation. Negotiations have not yet begun on the broader issue of how developing countries should be rewarded including consideration of the role of public funds and the many questions around carbon markets, their role and future and possible links to land-use emission reductions and removals by sinks.

- Accounting rules for LULUCF are complicated, fragmented and provide insufficient incentives for emission reductions and removals at scale. There is a risk that negotiations towards a more comprehensive accounting framework will result in a "race to the bottom" in response to concerns over domestic circumstances.

- Discussions on how forestry emissions can contribute towards emissions targets of developed countries have not even started. Depending on the overall architecture of a climate treaty, there is a real risk that LULUCF negotiations are again pushed to the end of the negotiations. 
- Many of the technical and scientific insecurities and concerns that complicated the negotiations in 1997 have been addressed, however, the land-use sector remains characterized by a greater level of MRV insecurity than industry or energy sectors. The question of permanence remains, and - outside of the CDM - has so far, not been appropriately discussed and, even less, addressed. Similarly, while there are methods on how to address national leakage of emissions, international leakage is completely ignored.

Advising on an environmentally sound way of treating land-use in a post-2020 treaty is further complicated by the many questions surrounding the overall architecture of a future climate regime. Considering the wide variety of interests and positions, and the likelihood that each country - or group of countries negotiating jointly - will aim to secure some negotiating successes, a complex and fragmented set of commitments and incentives is increasingly likely.

The binary world of the Kyoto Protocol, including its simple differentiation between developed and developing countries, between countries with and without targets, is likely to give way to a system of highly differentiated commitments following a pledge-and-review approach. From the review of country submissions and country interviews, a number of other assumptions may be formulated:

- There will be a variety of different commitments and land-use will figure differently within these commitments. Taking existing pledges as indicators for future commitments, developing countries will show a higher variety in the nature of their commitments than developed countries. There will be countries with economy-wide targets including or excluding forestry and agriculture. There will also be sectoral commitments, similar to existing pledges to reduce deforestation. These pledges will formulate absolute or relative emission reduction commitments. There will also be countries that commit to certain policies and measures in the land-use sector without quantifying associated emission reductions or removals.

- The overall integrity of land-use accounting depends on the integrity of its parts, i.e. the ambition of the activities and commitments as well as the accounting and MRV rules. Considering overall levels of uncertainty and the dynamics in international negotiations, accounting and MRV will remain prone to trade-offs. Countries that formulate economy-wide targets could use the land-use sector to gain some flexibility in meeting their targets. 
- There will be a range of incentives from project-based mechanisms to public results-based payments to reward developing country emission reductions. Public funds currently fall far short of overall needs and it has been a challenge to mobilize private sector funding at scale to support the reduction of emissions from land-use activities.

If we then consider the identified faultlines of land use post 2020: the differentiation between developed and developing countries; the integration of adaptation and mitigation within land-use strategies; and the coverage of all land-use emissions, i.e. from agriculture as well as forestry; as well as the need to build a system that is coherent and consistent across landscapes and countries while allowing for scaled up mitigation ambition and ensuring environmental integrity of the overall system, the following points emerge as essential within the current negotiations of a post-2020 framework:

- Policy coherence. There should be a set of harmonized clauses on land use. Complex provisions under one negotiation stream can be much better harmonized than individually and distantly negotiated clauses in a separate and fragmented set of agreements. LULUCF, REDD+, agriculture and any dedicated clauses on finance and incentives should be brought together and negotiated as one package. Commitments within this package will differ, but the various accounting and MRV frameworks should be consistent and facilitate vertical and horizontal integration across and within countries and over time.

- Consideration of different capabilities. Many developing countries lack the data, funds and capacities for land-use accounting. Countries should be supported in building the relevant capabilities and MRV rules should devise a system that encourages land-use reporting of all countries with rules creating more stringent requirements as capabilities increase. Developing countries with lower capabilities or low levels of land-use emissions can be encouraged to contribute to mitigation efforts, but should receive support with priority to adapt to climate change.

- Move towards full accounting. The final goal should be the full accounting of all land-based sources and emissions. Developed countries should either move directly to full landscape accounting or provide a timetable by when full wall-to-wall accounting will be possible. Integration should also allow countries to move from activity-based approaches (such as REDD+) to full landscape-level accounting. Such integrated systems could first be built on a sub- 
national basis and finally expand to cover as much of the national territory as possible (with a focus on regions with high emissions or high mitigation potential).

- Transparency should be encouraged, which means that incentives are set to encourage full reporting rather than encouraging countries to hold information back. Any moves to combine LULUCF and REDD+ accounting would need to proceed cautiously, ensuring that the current REDD+ framework is reinforced, rather than replaced, and that clear distinctions are made between the level of responsibility of developed and developing countries.

- Financial incentives for all land-use activities. This includes resultsbased payments by countries for all land-use activities, but also investments in carbon projects or dedicated policies and measures. Rules that allow the nesting of various accounting frameworks should be formulated and countries assisted to implement such frameworks. Rules for permanence should be formulated that allow for more fungibility of land-based emissions and removals. There should be a window for the land-use sector under the Green Climate Fund, considering that the land-use sector will require special consideration, incentives and accounting frameworks.

Overall land-use should be used to strengthen rather than weaken a future climate regime. Within this system differentiation is both achievable and needed. An overall system should account for differing capabilities and the need for financial incentives. Considering these differences, integration can follow a stepwise approach. There are plentiful opportunities for incremental integration that can help to consolidate the planning process and reduce the number of fragmented tracks.

Finally, there remains a risk that the lack of will and common understanding will lead once more to a complicated compromise with significant holes and gaps. This time, however, the differences would be less obvious and the chances for success greater. Since the negotiations of the Kyoto Protocol much knowledge has been built, data collected, and confidence gained. The trench between developing and developed countries has not disappeared, but it is now crisscrossed by a complex pattern of alliances - collaborating and opposing each other depending on 
their particular interests, constraints, and policy priorities. ${ }^{112}$ As a result, Parties' individual commitments may take many different forms reflecting national circumstances and capabilities. This variety of commitments and action would greatly benefit from an increased coherence in accounting and the alignment of incentive structures.

112 Jutta Brunné, Charlotte Streck (2013), The UNFCCC as a Negotiation Forum: Towards Common but More Differentiated Responsibilities, Climate Policy Special Issue on Changing Geopolitics of Climate Change, sep. 2013. 


\section{Sammanfattning}

Markanvändningssektorn erbjuder stora synergimöjligheter inom utsläppsminskningar, klimatanpassning, livsmedelssäkerhet och minskad fattigdom. Jordbruket, skogen och annan markanvändning står för $25 \%$ av de globala växthusgasutsläppen och skulle kunna bidra med stora kostnadseffektiva utsläppsminskningar och växthusgasupptag. Markanvändningssektorn fyller dessutom många viktiga funktioner för miljö och samhälle och ger försörjning för ungefär hälften av jordens befolkning. Markanvändning ställer oss dock också inför komplexa avvägningar och kompromisser mellan klimatarbete, livsmedelssäkerhet och handel. Klimatförändringarna kommer att förändra jordbruksproduktionen och påverka livsmedelspriserna vilket kommer att förändra de globala handelsflödena. Trots detta återstår frågan hur man kan hitta synergier mellan klimatanpassning, utsläppsminskningar och markanvändningssektorn inom ramen för global ekonomisk tillväxt.

Förhandlingarna kring ett framtida klimatavtal innebär en möjlighet att förbättra det nuvarande systemet och skapa ett gemensamt ramverk för utsläppsberäkningar och incitament för anpassnings- och utsläppsminskningsstrategier som täcker all markanvändning. FN:s ramkonvention för klimatförändringar [UN Framework Convention on Climate Change (UNFCCC)] har inte lyckats formulera en koherent vision för markanvändningssektorn, trots att konventionen erkänner sektorns speciella roll inom utsläppsminskningar och klimatanpassning. Istället har konventionen och Kyotoprotokollet etablerat olika regler, incitament och åtaganden för markanvändningssektorn som gör det svårt att forma konsekventa nationella strategier som beaktar hela sektorn och inte bara enskilda utsläppskällor. På grund av att markanvändning delas upp på dussintals olika agendapunkter och förhandlingsflöden vid de internationella klimatförhandlingarna finns det en risk, om inte särskilda ansträngningar görs, att det nuvarande systemet som inte beaktar markanvändningen i sin helhet kommer att finnas kvar i nästa klimatavtal.

Ett avtal för perioden efter 2020 måste ta hänsyn till tre centrala skiljelinjer. Åtaganden kan t.ex. handla om målsättningar för hela ekonomin, som antingen inbegriper eller utesluter skogsindustri och jordbruk. Eller 
också kan de göras i form av åtaganden för enskilda sektorer, på samma sätt som utfästelser att minska avskogningen. Dessa utfästelser skulle kunna bestå av absoluta eller relativa utsläppsminskningsåtaganden. Somliga länder kan anamma projektbaserade mekanismer liknande de som används i den nuvarande mekanismen för ren utveckling [Clean Development Mechanism (CDM)] och gemensamt genomförande [Joint Implementation (JI)]. Till slut kan länder välja att åta sig att införa styrmedel inom markanvändningssektorn utan att kvantifiera de medföljande utsläppsminskningarna och upptagen. Med nuvarande utsläppsminskningsutfästelser som indikatorer för framtida åtaganden kan utvecklingsländer komma att uppvisa större variation än industriländerna i vilken typ av åtaganden som görs för perioden efter 2020.

Helhetsintegriteten för markanvändningsberäkningarna hänger samman med integriteten hos de enskilda delarna, inklusive hur ambitiösa de aktiviteter och åtaganden som konventionsparterna lägger fram är, såväl som beräkningsintegriteten, samt integriteten för reglerna för mätning, rapportering och verifiering (MRV). Gällande markanvändningsregler är splittrade och omfattar många olika sorters omständigheter. Med beaktande av den generella osäkerheten och dynamiken vid internationella förhandlingar kan markanvändningssektorn komma att förbli öppen för kompromisser. Parterna kan komma att fortsätta använda sektorn för att få en viss flexibilitet $\mathrm{i}$ hur de möter sina åtagand en.

Ett avtal för perioden efter 2020 måste ta hänsyn till tre centrala skiljelinjer: utsläpp från markanvändningssektorn täcks fullständigt (d.v.s. både skog och jordbruk); länder differentieras enligt regeln för gemensamt men differentierat ansvar; utsläppsminskningar och anpassningsåtgärder integreras i markanvändningsstrategierna. Vidare måste systemet vara koherent och konsekvent för alla sorters landskap och alla länder, samtidigt som det gör det möjligt att öka ambitionerna kring utsläppsminskningar och säkerställa miljöintegriteten hos systemet som helhet. Mot den bakgrunden är följande punkter grundläggande för förhandlingarna kring ett ramverk för perioden efter 2020:

Det krävs harmoniserade, koherenta riktlinjer för markanvändning.Komplexa föreskrifter som samlas $\mathrm{i}$ ett förhandlingsflöde kan harmoniseras på ett mycket bättre sätt än enskilda klausuler som förhandlas åtskilda i separata och uppdelade avtal. Markanvändning, förändringar av markanvändning och skogsbruk [Land use, land-use change, and forestry (LULUCF)], minskade utsläpp från skogsavverkning och skogsförstörelse [Reduced Emissions from Deforestation and forest Degradation (REDD+)] och jordbruk, samt alla 
klausuler kring enbart finansiering och incitament skall samlas och förhandlas som ett paket. Åtaganden inom detta paket kommer att variera, men de olika beräknings- och MRV-ramverken måste vara konsekventa och underlätta vertikal och horisontell integration mellan och inom länder och över tidsperioder.

Utveckling i riktning mot fullständig beräkning. Slutmålet är att parterna utför fullständiga beräkningar för alla markbaserade källor och utsläpp. Parter med större ansvar och kapacitet måste antingen anamma fullständig landskapsberäkning omedelbart, eller ange ett tidsschema för när sådan fullkomlig beräkning kommer att bli möjlig. Parter med lägre kapacitet och mindre ansvar måste fortsätta med en aktivitetsbaserad metod (t.ex. REDD+) med flexibilitet att övergå till fullständig beräkning på landskapsnivå. Sådana integrerade system kan konstrueras på subnationell nivå först, och sedan expanderas så att de täcker så stor nationell yta som möjligt (med fokus på regioner med stora utsläpp eller stor potential för utsläppsminskningar).

Beaktande av olika kapaciteter. Många utvecklingsländer saknar de data, resurser och kapacitet som krävs för markanvändningsberäkningar. Länder måste få stöd med att bygga upp relevant kapacitet, och MRVreglerna måste konstruera ett system som uppmuntrar till markanvändningsberäkningar för alla länder med regler som skapar strängare krav allteftersom kapaciteten ökar. Utvecklingsländer med lägre kapacitet eller lägre nivåer av markanvändningsutsläpp kan uppmuntras till att bidra till utsläppsminskningar och upptag, men stöd till anpassning skall prioriteras.

Transparens måste uppmuntras; detta innebär att incitament skapas för att uppmuntra till fullständig beräkning istället för att uppmuntra länder att hålla inne med information.Ansatser till att kombinera LULUCF- och REDD+-beräkningar måste göras försiktigt och säkerställa att det nuvarande REDD+-ramverket stärks, inte ersätts, samt att tydliga åtskillnader görs mellan utvecklings- och industriländers ansvarsnivåer.

Ekonomiska incitament måste finnas tillgängliga för all markanvändningsaktivitet. Detta omfattar resultatbaserade betalningar för utsläppsminskningar i samband med markanvändning, men även investeringar i klimatkompensationsprojekt eller styrmedel och åtgärder avsedda för detta ändamål. Regler som tillåter att enskilda beräkningsramverk används inom större, mer omfattande, ramverk måste formuleras och länder måste få hjälp med att implementera sådana ramverk. Reglerna för permanens måste ge mer utrymme för fungibilitet kring markbaserade utsläpp och upptag. Det måste finnas ett fönster för markanvändningssektorn under den gröna klimatfonden 
[Green Climate Fund (GCF)], med tanke på att markanvändningssektorn kräver särskilt beaktande, incitament och beräkningsramverk.

Markanvändningssektorn måste användas för att stärka, ej försvaga, en framtida klimatregim. Inom detta system krävs differentiering, och detta kan även åstadkommas. Ett helhetssytem måste ta hänsyn till skilda kapaciteter och till att ekonomiska incitament behövs. Med hänsyn till dessa skillnader kan integrering ske i etapper. Det finns gott om möjligheter för stegvis integrering så att det blir lättare att hålla samman planeringsarbetet och minska antalet sidospår.

Slutligen finns det fortfarande en risk att bristen på politisk vilja och samförstånd åter kommer att leda till en mer komplicerad kompromiss med stora hål och sprickor. Denna gång skulle skillnaderna dock vara mindre och möjligheterna att lyckas desto större. Efter Kyotoförhandlingarna har vi lärt oss mer, samlat mer information och ökat vårt självförtroende. Klyftan mellan utvecklings- och industriländer har inte försvunnit, men den binds nu samman kors och tvärs genom komplexa allianser - samarbeten och motsättningar beroende på enskilda intressen, begränsningar och politiska prioriteringar. Följden blir att en parts åtaganden kan ha flera olika former som återspeglar nationella omständigheter och kapacitet. Den här mångfalden bland åtaganden och handlingar skulle må mycket bra av att beräkningsprocedurer och incitamentsstrukturer blev mer konsekventa. 


\section{Annex I: List of Parties' submissions}

Submissions to the ADP under Workstream 1 on general mitigation under a post-2020 agreement (All submissions are available at: http://unfccc.int) bodies/awg/items/6656.php)

- African Group - Submission by Swaziland on behalf of the African Group under Workstream 1 of the ADP, 8th October 2013.

- Australia - The 2015 climate change agreement, 26th March 2013.

- Brazil - Overall views of the ADP "workstream 1" process and outcome, 12th September 2013.

- Environmental Integrity Group (EIG) - 2015 Agreement: contours and core elements, specific views in the area of mitigation, adaptation and means of implementation, and respective deliverables in 2013, and planning of work 2014/2015, 23rd September 2013.

- European Union - The scope, design and structure of the 2015 agreement, 16th September 2013.

- India - Submission by India on the work of the Ad Hoc Working Group on the Durban Platform for Enhanced Action: Workstream I, 13th September 2013.

- Japan - Information, views and proposals on matters related to the work of Ad Hoc Working Group on the Durban Platform for Enhanced Action, 10th September 2013.

- Least Developed Countries - Submission by Nepal on behalf of the Least Developed Countries Group on the ADP Workstream 1: The 2015 Agreement, Building on the Conclusions of the ADP 1-2, 3rd September 2013.

- Like Minded Developing Countries - LMDC views on identification of elements in ADP Workstream 1, 18th November 2013.

- New Zealand - New Zealand Submission to the Ad Hoc Working Group on the Durban Platform for Enhanced Action, 15th October 2013.

- South Africa - South African submission on mitigation, 30th September 2013.

- South Africa - Submission by South Africa, 27th April 2013. 
- United States of America - U.S. Submission on the 2015 Agreement, 17th October 2013.

Submissions to the SBSTA on the New Market-based Mechanism (Submissions available at: http://unfccc.int/cooperation_support/market_and_non-market _mechanisms/items/7710.php).

- Coalition for Rainforest Nations - Submission by the Coalition for Rainforest Nations on the new market-based mechanism, 15th September 2013.

- European Union - Submission by the European Union on the new market-based mechanism, 12th September 2013.

- Least Developed Countries - Submission on the work programme on modalities and procedures for a new market-based mechanism, operating under the guidance and authority of the Conference of the Parties - Views on the matter referred to in paragraphs 83 and 84 of the Durban AWG-LCA conclusions by the Gambia on behalf of the Least Developed Countries, 2012.

- United States of America - Submission of the United States on UNFCCC New Market Mechanisms, 9th March 2012.

- AOSIS - Submission by AOSIS, 12th November 2013.

- Bolivia - Submission by the plurinational State of Bolivia, 8th November 2013.

Submissions to the SBSTA on the Framework for Various Approaches (Submissions available at: http://unfccc.int/cooperation_support) market_and_non-market_mechanisms/items/7709.php).

- AOSIS - Various approaches, including opportunities for using markets, to enhance the cost-effectiveness of, and to promote, mitigation actions, bearing in mind different circumstances of developed and developing countries, 7th May 2013.

- Australia - Views on a framework for various market and nonmarket based approaches to mitigation, 29th August 2012.

- Bolivia - Submission by the Plurinational State of Bolivia, 3rd September 2013.

- Coalition for Rainforest Nations - Submission by the Coalition for Rainforest Nations on the Framework for Various Approaches, 15th September 2013.

- United States - Submission of the United States on an International Framework to Address "Various Approaches", 9th March 2012. 
Submissions to the SBSTA on more comprehensive accounting of LULUCF emissions under the Kyoto Protocol (Submissions available at: http:// unfccc.int/documentation/submissions_from_parties/items/8017.php)

- African Group - Submission to SBSTA by the governments of Swaziland on behalf of the Africa Group on issues relating to a more comprehensive accounting of anthropogenic emissions by sources and removals by sinks from LULUCF, Including through a more inclusive activity-based approach or a land-based approach, 2nd April 2013.

- Australia - Issues related to more comprehensive accounting of anthropogenic emissions by sources and removals by sinks from land-use, land-use change, and forestry, including through a more inclusive activity-based approach or a land-based approach, 14th September 2012.

- China - China's Submission on the Issues Related to the Agenda Item on LULUCF under SBSTA, 27th September 2013.

- COMIFAC - Submission of the Congo Basin Countries, 24th March 2013.

- European Union - Submission on issues related to a more comprehensive accounting of anthropogenic emissions by sources and removals by sinks from LULUCF, including through a more inclusive activity-based approach or a land-based approach, as referred to in decision 2/CMP.7, paragraph 5, 16th July 2012.

- Indonesia - Land use, land-use change and forestry under Article 3, paragraphs 3 and 4, of the Kyoto Protocol and under the clean development mechanism, 23rd April 2013.

- Japan - Submission by the Government of Japan: Further views on issues related to Land use, land-use change and forestry (LULUCF) as mentioned in paragraphs 116-118 of document FCCC/SBSTA/2012/2 and paragraph 5 of document FCCC/SBSTA/2012/L.30, 19th April 2013.

- New Zealand - Initial views on Issues related to more comprehensive LULUCF accounting, 24th April 2013.

- Pakistan - Government of Pakistan, Ministry of Climate Change Submission on LULUCF, 27th March 2013. 
Submissions to the SBSTA on the inclusion of additional LULUCF activities under the CDM (Submissions available at: http://unfccc.int/documentation/ submissions_from_parties/items/8017.php)

- China - China's Submission on the Issues Related to the Agenda Item on LULUCF under SBSTA, 27th September 2013.

- Submission by Nepal on behalf of the Least Developed Countries Group on the SBSTA agenda item relating to methodological issues under the Kyoto Protocol: Land Use, Land Use Change and Forestry under Article 3, paragraphs 3 and 4, of the Kyoto Protocol and under the Clean Development Mechanism, 18th October 2013.

- COMIFAC - Submission of the Congo Basin Countries, 24th March 2013.

Submissions to SBSTA on issues relating to agriculture (Submissions available at: http://unfccc.int/documentation/submissions_from_parties/items/8017.php)

- Africa Group - SBSTA submission on issues relating to agriculture, 3rd September 2013.

- Australia - Issues related to Agriculture, 2nd May 2012.

- Bangladesh - Submission by Bangladesh Pursuant to COP Decision in Durban on "Outcome of the Work of the AWGLCA under the Convention" in paragraphs 75 and 76 on Cooperative and Sectoral Approaches, 15th May 2012.

- China - China's submissions on the matters referred to the Decisions adopted by COP17/CMP7, 8th March 2012.

- European Union - Submission on enhanced action on mitigation, cooperative sectoral approaches and sector specific actions, in order to enhance the implementation of Article 4, paragraph 1(c), of the Convention: - Views from Parties on the issues related to agriculture referred to in paragraph 751 of decision [-/CP 17] Outcome of the work of the Ad Hoc Working Group on Long-term Cooperative Action under the Convention, 5th March 2012.

- Independent Alliance of Latin America and the Caribbean - Subsidiary Body for Scientific and Technical Advice (SBSTA) Agenda Item: Matters related to Agriculture, 10th October 2013.

- Japan - Submission from Japan, 27th February 2012.

- New Zealand submission to the Subsidiary Body for Scientific and Technological Advice: Views on issues related to agriculture, 23rd March 2012.

- United States of America - Submission by the United States of America: Issues Related to Agriculture, 6th March 2012. 


\section{Annex 2: Land use pledges under the Copenhagen Accord}

(Submissions available at: http://unfccc.int/meetings/cop_15/ copenhagen_accord/items/5265.php_) 


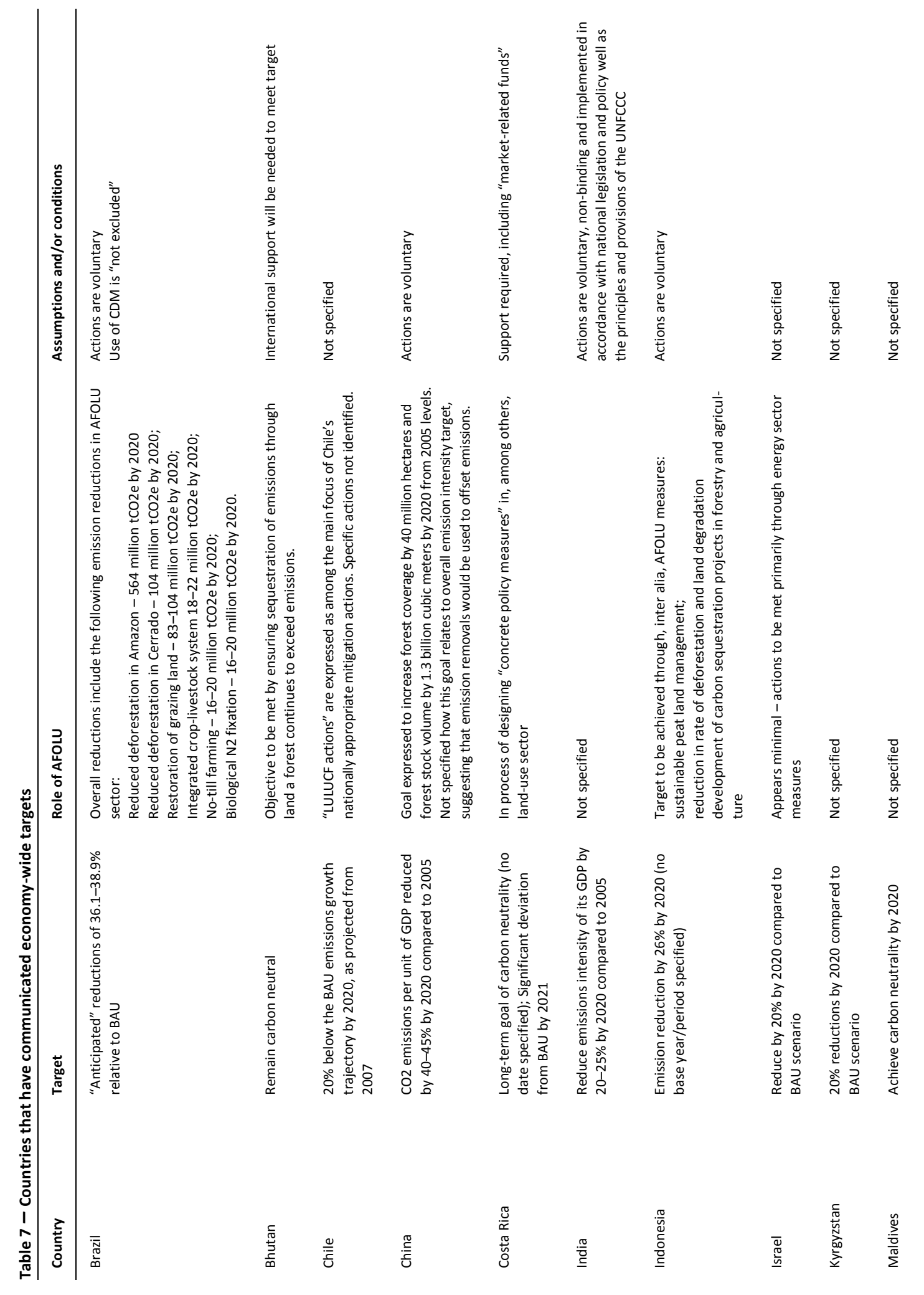



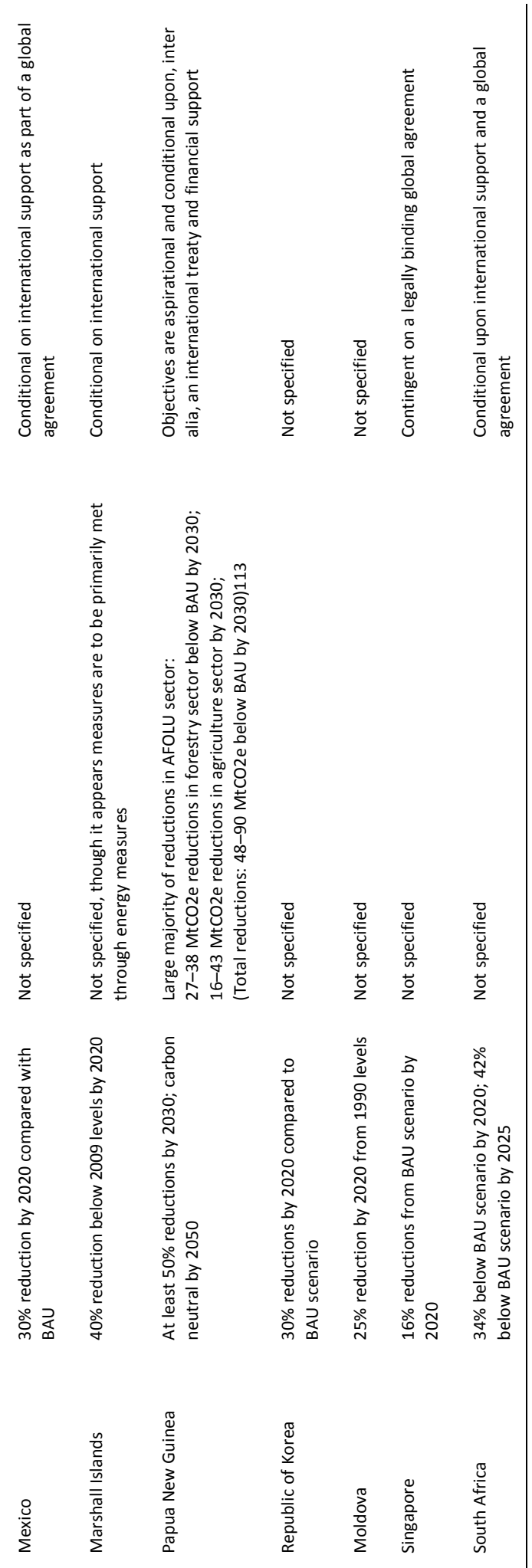


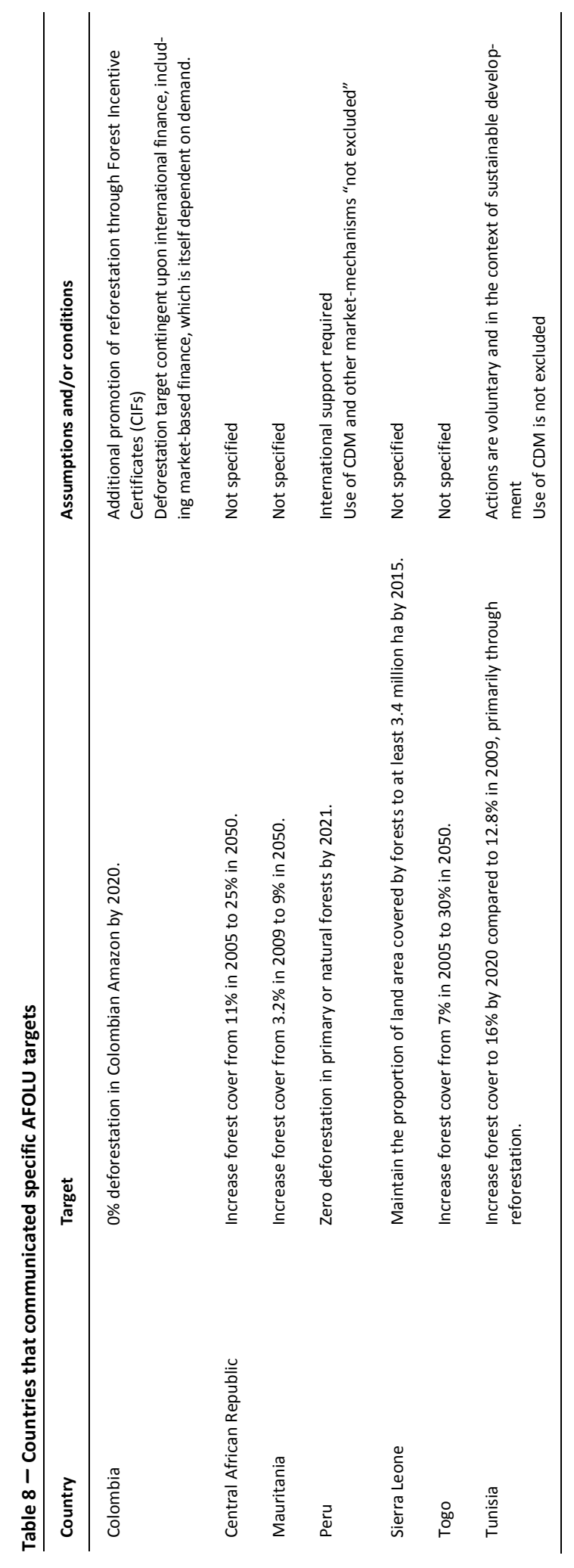




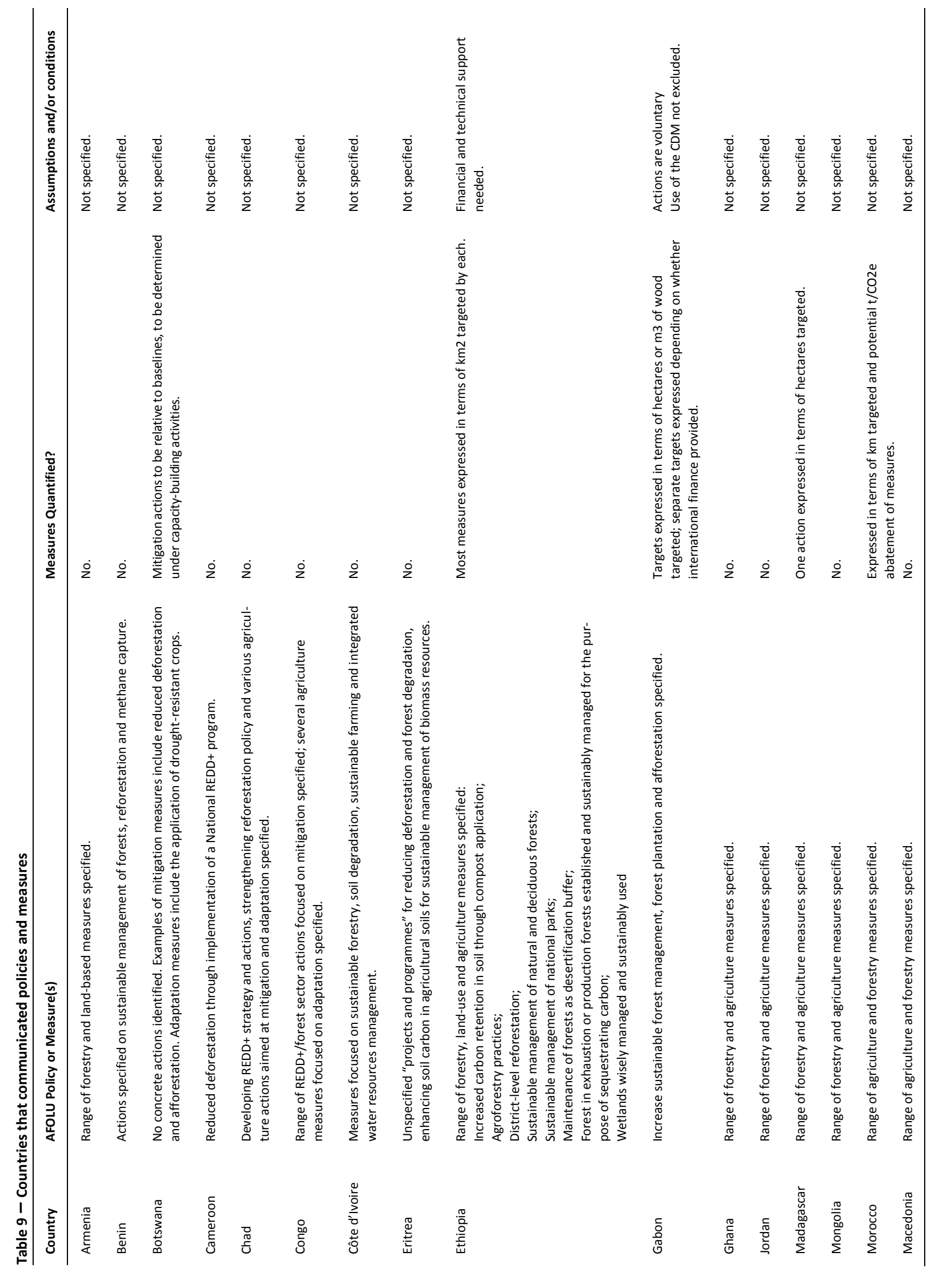


Ved Stranden 18

DK-1061 Copenhagen K

www.norden.org

\section{The land-use sector within the post-2020 climate regime}

The land-use sector serves key environmental and social functions and supports the livelihoods of around a half of the world's population. Despite its importance, however, the climate regime fails to formulate a coherent vision or set of incentives for mitigation and adaptation from the sector. The negotiation of a future climate treaty that will take effect in 2020 presents a key opportunity to improve the current system and create an integrated accounting and incentive framework for adaptation and mitigation strategies across all land-uses.

This report - conducted by Climate Focus together with UNIQUE forestry and land use - analyses the current status of the landuse sector under the United Nations Framework Convention on Climate Change and its Kyoto Protocol, and formulates options for how various incentives and systems could be harmonized under a future climate treaty.

TemaNord 2014:520

ISBN 978-92-893-2751-0

ISBN 978-92-893-2752-7 (EPUB)

ISSN 0908-6692
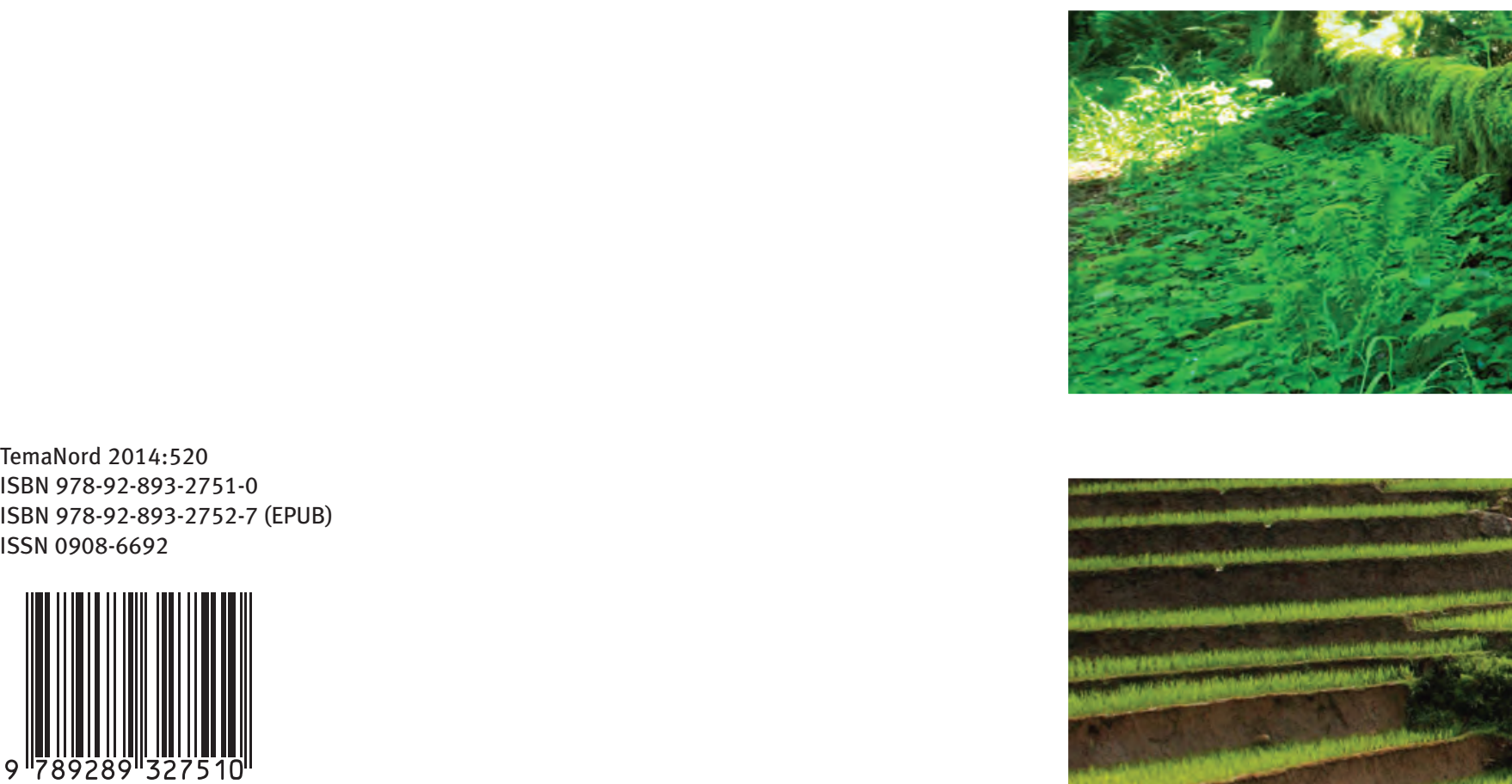